\title{
DISCURSO PRESIDENCIAL COSTARRICENSE: ESTRUCTURA FORMAL Y TÓPICA DEL ÚLTIMO MENSAJE ANTE LOS DIPUTADOS (1902-2002)
}

\author{
Carla Victoria Jara Murillo
}

\begin{abstract}
RESUMEN
El objetivo de este artículo es analizar un tipo particular de discurso político, a saber, el último mensaje del presidente de la República, presentado el $1^{\circ}$ de mayo ante la asamblea de los diputados, durante el período 1902-2002. Los aspectos que se consideran son la estructura formal del mensaje y su contenido o tópica. La estructura formal se analiza en términos de tres subestructuras: título, marco y discurso. La tópica se entiende, siguiendo la propuesta de Teun van Dijk (1999), como el conjunto de los temas recurrentes en el discurso. Estos se desarrollan en las tres secuencias que conforman el discurso: exordio, cuerpo y epílogo.

Palabras clave: análisis del discurso, discurso político, estructura formal, tópica, política costarricense.
\end{abstract}

\begin{abstract}
The goal of this article is to analyze a particular type of political discourse, namely the last speech given by the president on May $1^{\text {st }}$ to the Congress, during the period 1902-2002. The analysis is focused on the formal structure and the content of these speeches. Formal structure is analyzed in terms of three sub-structures: title, frame and discourse. Discourse content is viewed, following Teun van Dijk (1999), as the array of recurrent themes in the set of texts. These are developed in three sequences conforming the discourse: exordium, body and epilogue.

Key words: discourse analysis, political discourse, formal structure, content, Costa Rican politics.
\end{abstract}

\section{Introducción}

\subsection{Objeto, corpus y objetivo}

Este artículo es el primero derivado de la investigación "Análisis del Discurso Político en Costa Rica: Evolución y Perspectiva”, inscrita en el Instituto de Investigaciones Linguuísticas de la Universidad de Costa Rica con el número 745-A4-100.

Carla Victoria Jara Murillo. Profesora de la Escuela de Filología, Lingüística y Literatura, Universidad de Costa Rica. San Pedro, San José, Costa Rica.

Correo electrónico: cjara@cariari.ucr.ac.cr, cvjara@yahoo.com

Recepción: 19- 12- 2007

Aceptación: 14- 1- 2008 
El material que compone el corpus de estudio son los Mensajes Presidenciales (en adelante MPs) ${ }^{1}$ presentados ante la asamblea de los diputados ${ }^{2}$ el último $\mathbf{1}^{\mathbf{0}}$ de mayo de cada administración (excepto por el del 16 de enero de 1949, sesión de instalación de la Asamblea Constituyente), por el período que va de 1902 al 2002.

Por lo tanto el corpus se compone de $28 \mathrm{MPs}$, correspondientes a los períodos administrativos y los expresidentes que se enlistan en la Tabla 1 (v. sección 2.3).

El proyecto contempla una serie de objetivos entre los cuales figuran los siguientes:

1. Descripción del evento comunicativo desde la etnografía de la comunicación (Hymes 1972)

2. Descripción de la forma y el contenido del MP:

a. Estructura formal

b. Contenido o tópica

c. Análisis léxico

3. Análisis de los participantes y sus roles (van Dijk 1998)

4. Análisis de la intertextualidad

5. Análisis del componente ideológico

El presente artículo se concentra en los puntos a) y b) del segundo objetivo: forma y contenido del mensaje. La estructura formal se analiza en términos de tres subestructuras: título, marco (que consta de saludo y cierre) y discurso. La tópica se entiende aquí, siguiendo a van Dijk (1999), como el conjunto de los temas recurrentes en el discurso. Se verá que estos temas se desarrollan en tres partes principales o secuencias: exordio, cuerpo y epílogo. Más allá de las secuencias, el discurso se segmenta en otras tres unidades temáticas: segmentos (Sn), subsegmentos (Sn.n) y párrafos (Pn). El Cuadro 1 muestra la relación entre las unidades señaladas para la descripción de la forma y el contenido del MP:

Cuadro 1. Unidades de análisis

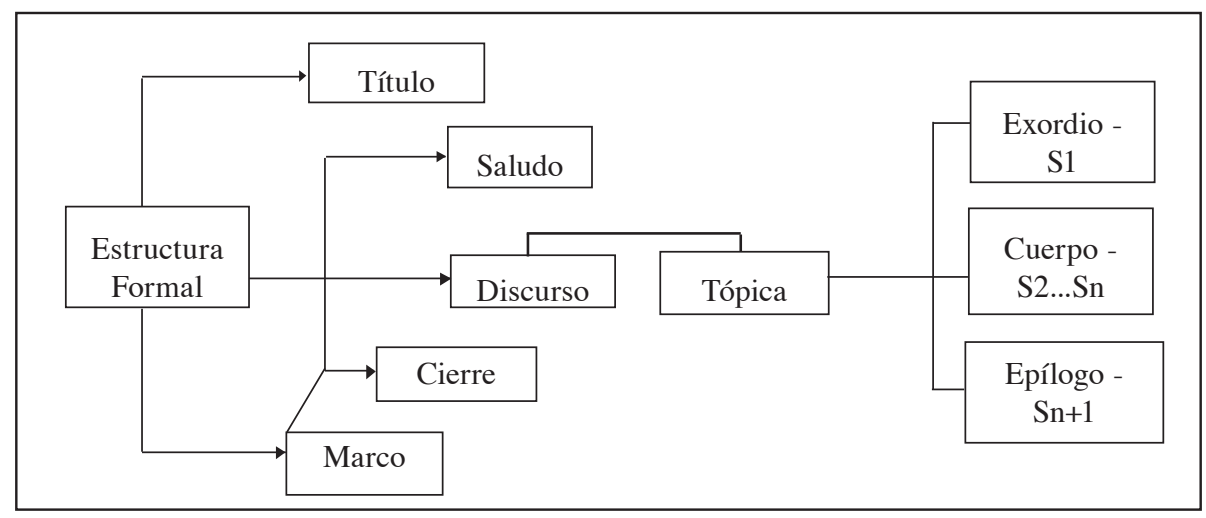

\subsection{Estado de la cuestión}

Se ha recopilado una serie de textos nacionales que analizan discurso político costarricense, los cuales, sin embargo, no se enmarcan propiamente dentro de la disciplina lingüística (Fernández 1989, Quesada Camacho 1989, González 1994, Sánchez Duarte 1998, Jiménez Ardón 1993, Arguedas 2000, Hernández 2000). Dentro de la corriente lingüística, se encuentran Hernández Mata (1995) y Quesada Pacheco (1989, 1994, 1997, 2001). Los trabajos 
de Quesada Pacheco se concentran en el análisis de la persuasión en discursos electorales, lo cual dista mucho de mi objeto de estudio y de mi enfoque.

Se han identificado algunas tesis que analizan el discurso presidencial, como son Mena y Soto (1997), Zeledón Torres (1991) y Zamora Ovares (2000); sin embargo, cabe destacar que la única dentro del campo de la lingüística que se ha encontrado es Pendones de Pedro (1991), trabajo que se enfoca en el ámbito centroamericano.

\section{El discurso político}

\subsection{Dimensiones}

De acuerdo con van Dijk (1999), para analizar el discurso político es necesario observarlo en sus tres dimensiones complementarias:

1. La naturaleza de los participantes: "el discurso político es aquello dicho por sus actores o autores, los políticos" (1999: 12).

2. La naturaleza de las acciones o prácticas que realiza el texto político en cuestión.

3. La naturaleza del contexto: "Los participantes y las acciones son el núcleo de tales contextos, pero podríamos ir más lejos analizando los contextos ampliamente desde el punto de vista de los sucesos políticos y comunicativos con sus escenarios propios (tiempo, lugar y circunstancias), ocasiones, intenciones, funciones, metas e implicaciones políticas o legales" (1999: 15).

Entre las funciones que cumple el discurso político, van Dijk señala "elaborar o influir decisiones políticas (...), la distribución de recursos sociales, el establecimiento o cambio de normas, regulaciones y leyes, etc." (1999: 16).

Van Dijk ofrece una definición contextual del discurso político y aclara que este no se reduce necesariamente al discurso de los políticos oficiales (naturaleza de los participantes), sino que es el contexto lo que define determinado discurso como político:

\footnotetext{
...el actuar político y el discurso, en consecuencia también político, se definen en esencia contextualmente, desde el punto de vista de las prácticas o sucesos especiales donde fines, metas o funciones son, quizá no exclusivamente pero por lo menos primariamente, políticas. Esto excluye el habla de los políticos fuera de los contextos políticos, mientras que incluye el discurso de todos los otros grupos, instituciones o ciudadanos tan pronto como ellos participen en sucesos políticos. (van Dijk 1999:17).
}

De acuerdo con esta definición de discurso político, el objeto de estudio de este proyecto, esto es, cada uno de los $28 \mathrm{MPs}$, puede ser visto como un ejemplar prototípico de discurso político; lo es en términos de los participantes involucrados, de la naturaleza de la acción que realiza y de la naturaleza del contexto espacio-temporal y simbólico en que se desarrolla. En términos de sus dimensiones integrales, el MP es esencial y representativamente político.

\subsection{Acciones que realiza el texto político}

La acción que realiza el MP es acatar el mandato constitucional que se establece en el Título X "El Poder Ejecutivo", Capítulo II “Deberes y Atribuciones de quienes ejercen el Poder Ejecutivo", Artículo 139, inciso 4. El Cuadro 2 presenta el contenido del artículo (mi énfasis): 
Cuadro 2. Artículo 139 de la Constitución Política de Costa Rica

\section{TITULO X \\ EL PODER EJECUTIVO \\ CAPITULO II}

Deberes y Atribuciones de quienes ejercen el Poder Ejecutivo

ARTÍCULO 139.- Son deberes y atribuciones exlusivas de quien ejerce la Presidencia de la República:

1) Nombrar y remover libremente a los Ministros de Gobierno;

2) Representar a la Nación en los asuntos de carácter oficial;

3) Ejercer el mando supremo de la fuerza pública;

4) Presentar a la Asamblea Legislativa, al iniciarse el primer período anual de sesiones, un mensaje escrito relativo a los diversos asuntos de la Administración y al estado político de la República y en el cual deberá, además, proponer las medidas que juzgue de importancia para la buena marcha del Gobierno, y el progreso y bienestar de la Nación;

5) Comunicar de previo a la Asamblea Legislativa, cuando se proponga salir del país, los motivos de su viaje. (Así reformado este inciso por Ley No. 7674 del 17 de junio de 1997)

Desde un punto de vista eminentemente político, es necesario ubicar el MP dentro del conjunto de las acciones políticas del Poder Ejecutivo en Costa Rica. En este sentido, Rojas (1980) define los mensajes presidenciales como parte de las "atribuciones políticas del Poder Ejecutivo" (segunda parte de su libro), y los ubica entre "los poderes del Ejecutivo como colegislador". Rojas describe los siguientes poderes del Ejecutivo:

1. La iniciativa en la formación de la ley

2. Convocatoria a sesiones extraordinarias

3. Mensajes e informes

4. Asistencia de ministros al plenario

5. La fase integrativa de la eficacia de la ley (sanción, promulgación y veto)

Específicamente sobre los mensajes, nos dice:

...en el Estado moderno por cuestiones técnicas, económico-sociales, el Poder Ejecutivo debe informar a la Asamblea para que ella tome una decisión adecuada a los problemas planteados. Tal obligación de informar está prevista en la Constitución Política.

El artículo 139 exige al Presidente -obligación exclusiva suya-, presentar a la Asamblea Legislativa, al iniciarse el primer período anual de sesiones, un mensaje escrito relativo a los diversos asuntos de la Administración y al estado político de la República. En este informe deberá, además, proponer las medidas que juzgue de importancia para la marcha del Gobierno y el progreso y bienestar de la Nación. Esta obligación se le impone al Presidente por ser el Jefe de Estado y jefe de la Administración, pero tiene evidente conexión con las atribuciones del Poder Ejecutivo, como órgano semicolegiado. (...)Esta obligación del Presidente es, pues, un medio de acción importante del Poder Ejecutivo.

El Mensaje Presidencial engloba las memorias de cada Ministerio, lo que no exime a los Ministros del deber de presentar un informe al Poder Legislativo a más tardar quince días después de iniciado el primer período de sesiones ordinarias. (...) El informe es anual pero el Ministro está obligado a presentar explicaciones a la Asamblea cuando ésta lo juzgue necesario, con lo cual también informa. Como medio de control, las explicaciones e informes son más importantes que la Memoria Anual de cada Ministerio, ya que ésta y el Mensaje Presidencial no son analizados por la mayoría de los diputados, quienes muchas veces no los escuchan ni leen. Sin embargo, debe tenerse en cuenta su valor como medio de comunicación entre ambos Poderes Políticos (Rojas 1980: 109-110). 
En resumen, el texto que aquí se identifica como MP constituye el segmento final de una comunicación periódica, oficial y obligatoria emitida por el gobierno en ejercicio a lo largo de su período de mandato, esto es, cuatro años en el sistema político costarricense. En cuanto al contenido, el texto enumera las acciones que ha ejecutado el gobierno en mayor o menor detalle a lo largo de un lapso específico. Esta acción expositiva se entrelaza en el discurso con otros tipos de acción política discursiva como son la actualización de la ideología, la legitimación, etc., aspectos que serán analizados en los próximos artículos derivados de esta investigación.

Los mensajes presidenciales son cuatro en total, uno por año, y se presentan en la fecha específica del $1^{\circ}$ de mayo. La acción que realizan se define en términos de sus características específicas. Si bien las características generales son las mismas para cada uno de los cuatro, el MP tiene características particulares por ser el último, esto es, la última oportunidad del emisor de cumplir con su obligación de informar a la ciudadanía sobre la labor efectuada y de convencerla del resultado positivo de su gobierno. Dos factores interdependientes son esenciales:

1. Acumulación: por ser el último, el MP tendrá necesariamente un carácter acumulativo.

2. Perfectividad: el MP tendrá, a diferencia de los tres informes anteriores, un carácter perfectivo y conclusivo. Las acciones políticas que el gobierno estableció en su plan de trabajo se habrán cumplido en mayor o menor grado, sin que haya posibilidad de que nada se pueda modificar, extender ni proyectar. El emisor así presenta un estado de cosas acabado. Esta vendría a ser la diferencia fundamental con los previos informes, en los que el estado de cosas se presenta en proceso. A pesar de que se hace énfasis en las acciones desarrolladas en el último año de gobierno, el MP en última instancia da cuenta de la labor total efectuada en un período gubernamental de cuatro años.

\subsection{Ubicación del MP en el dominio de la política nacional}

Siguiendo a van Dijk (1999) y de acuerdo con su definición de las categorías que conforman el dominio de la política, podemos caracterizar el objeto de estudio de esta investigación de la siguiente manera:

Dominio: la política nacional

Valores: cumplimiento de las metas establecidas en el plan de gobierno; transparencia en el accionar del gobierno

Sistema: principalmente democracia (por excepción: dictadura y proceso revolucionario)

Ideología: variable según el partido en el gobierno (cp. Salazar Mora y Salazar Mora 1991)

Instituciones: Presidencia, Congreso / Asamblea Legislativa (en el contexto inmediato)

Organizaciones: partido en el gobierno, partidos representados en la Asamblea Legislativa (en el contexto mediato)

Grupos: grupo ideológico en el poder, ciudadanía (en el contexto más general)

Actores: el Presidente saliente y su equipo de gobierno

Relación política: el mandato constitucional de informar o dar cuenta al país sobre las acciones del gobierno

Proceso político: la administración de un periodo de gobierno

Acción política: informar, dar cuenta de las acciones del gobierno

Cogniciones políticas: el deber de sentar las responsabilidades de la acción política 
Tabla 1. Partido, Administración, Presidente y Fecha de los MPs

\begin{tabular}{|c|c|c|c|}
\hline Partido político & Administración & Presidente & Fecha del MP \\
\hline Partido Civil & $1898-1902$ & Rafael Iglesias Castro & 1o. de mayo de 1902 \\
\hline Partido Unión Nacional & $1902-1906$ & Ascensión Esquivel Ibarra & 1o. de mayo de 1906 \\
\hline Partido Unión Nacional & $1906-1910$ & Cleto González Víquez & 1o. de mayo de 1910 \\
\hline Partido Republicano & 1910-1914 & Ricardo Jiménez Oreamuno & 1o. de mayo de 1914 \\
\hline Partido Republicano & 1914-1917 & Alfredo González Flores & 1o. de mayo de 1916 \\
\hline (golpe de estado) & $1917-1919$ & Federico Tinoco Granados & 1o. de mayo de 1919 \\
\hline Partido Republicano & $1919-1920$ & Francisco Aguilar Barquero & 1o. de mayo de 1920 \\
\hline Partido Repúblicano & 1920-1924 & Julio Acosta García & 1o. de mayo de 1924 \\
\hline Partido Republicano & $1924-1928$ & Ricardo Jiménez Oreamuno & 1o. de mayo de 1928 \\
\hline Partido Unión Nacional & 1928-1932 & Cleto González Víquez & 1o. de mayo de 1932 \\
\hline P. Republicano Nacional & $1932-1936$ & Ricardo Jiménez Oreamuno & 1o. de mayo de 1936 \\
\hline P. Republicano Nacional & $1936-1940$ & León Cortés Castro & 1o. de mayo de 1940 \\
\hline P. Republicano Nacional & $1940-1944$ & Rafael Ángel Calderón Guardia & 1o. de mayo de 1944 \\
\hline P. Republicano Nacional & $1944-1948$ & Teodoro Picado Michalski & 1o. de mayo de 1947 \\
\hline (proceso revolucionario) & $1948-1949$ & José Figueres Ferrer & 16 de enero de 1949 \\
\hline Partido Unión Nacional & $1949-1953$ & Otilio Ulate Blanco & 1o. de mayo de 1953 \\
\hline P. Liberación Nacional & 1953-1958 & José Figueres Ferrer & 1o. de mayo de 1958 \\
\hline Partido Unión Nacional & $1958-1962$ & Mario Echandi Jiménez & 1o. de mayo de 1962 \\
\hline P. Liberación Nacional & $1962-1966$ & Francisco Orlich Bolmarcich & 1o. de mayo de 1966 \\
\hline P. Unificación Nacional & $1966-1970$ & José Joaquín Trejos Fernández & 1o. de mayo de 1970 \\
\hline P. Liberación Nacional & $1970-1974$ & José Figueres Ferrer & 1o. de mayo de 1974 \\
\hline P. Liberación Nacional & $1974-1978$ & Daniel Oduber Quirós & 1o. de mayo de 1978 \\
\hline Coalición Unidad & 1978-1982 & Rodrigo Carazo Odio & 1o. de mayo de 1982 \\
\hline P. Liberación Nacional & $1982-1986$ & Luis Alberto Monge Álvarez & 1o. de mayo de 1986 \\
\hline P. Liberación Nacional & $1986-1990$ & Óscar Arias Sánchez & 1o. de mayo de 1990 \\
\hline P. Unidad Socialcristiana & $1990-1994$ & Rafael Ángel Calderón Fournier & 1o. de mayo de 1994 \\
\hline P. Liberación Nacional & 1994-1998 & José María Figueres Olsen & 1o. de mayo de 1998 \\
\hline P. Unidad Socialcristiana & $1998-2002$ & Miguel A. Rodríguez Echeverría & 1o. de mayo de 1902 \\
\hline
\end{tabular}

\subsection{Niveles de análisis en el texto político}

\subsubsection{Léxico y sintaxis}

Una de las características más prominentes de los estudios del discurso político es que en una gran mayoría se enfocan en el nivel léxico. Esto se debe al hecho de que el vocabulario es la parte de la lengua más fácilmente identificable como propia de un determinado dominio; lo mismo es válido para otros tipos de discurso como el educativo, médico, legal, deportivo, etc. Como ya se señaló, en un segundo artículo derivado de este proyecto se presentará el análisis léxico del corpus en estudio.

De acuerdo con van Dijk (1999), la manipulación de la sintaxis es menos obvia que la del léxico; sin embargo, el uso de los pronombres, el orden de palabras, ciertas categorías sintácticas específicas como la construcción pasiva, la nominalización, la subordinación, etc., permiten expresar significados coherentes con los objetivos concretos del discurso político. 
En particular se han hecho estudios sobre el uso de los pronombres: las oposiciones nosotros/ ellos, yo/ustedes, yo/nosotros han recibido particular atención de parte de los lingüistas/ analistas del discurso político.

\footnotetext{
El uso político del plural nosotros (o de los posesivos nuestros) tiene muchas implicaciones para la posición política, las alianzas, la solidaridad y la otra posición socio-política del hablante, dependiendo de la pertinente cohesión del grupo interno que puede estar siendo construido en el contexto actual: nosotros en occidente, nosotros el pueblo, nosotros los ciudadanos americanos, nosotros demócratas, nosotros que estamos en el gobierno, o desde luego nosotros el presidente (van Dijk 1999:56).
}

El estudio de la deixis personal y el tema general de la enunciación en el tipo de discurso que me ocupa será tratado en un artículo posterior, correspondiente al objetivo arriba señalado: "Análisis de los participantes y sus roles", en el marco de la teoría del contexto de van Dijk $(1998,2001)$.

\subsubsection{Temas}

Gran parte del discurso político trata sobre temas políticos, lo cual significa que en gran parte el discurso político es reflexivo. Entre estos temas encontramos manifestaciones sobre los sistemas, ideologías, instituciones, procesos, actores y eventos políticos. Más concretamente, en la campaña el candidato hablará sobre sí mismo y sobre las políticas que apoyará en una eventual administración suya. Se hablará también, y contrastivamente, sobre los adversarios políticos y sus malas o inadecuadas gestiones y puntos de vista políticos. (El componente ideológico y sus manifestaciones en el MP serán tratados en un artículo posterior, correspondiente al quinto de los objetivos citados en 1.1).

En segundo lugar, el discurso político combina los temas reflexivos con una serie de temas propios de otros dominios o campos sociales como la educación, la salud pública, la seguridad ciudadana, etc. De hecho, en este sentido, no habría límite para las temáticas de que se ocupa el discurso político. Sin embargo, advierte van Dijk, a pesar de la diversidad de temas de que puede tratar el discurso político, es necesario pensar que se pueden establecer limitaciones en lo que llama la "tópica", esto es, los temas a los que hace referencia determinado tipo de discurso (1999: 40). Es objetivo de este artículo tratar de establecer esa tópica para el MP costarricense del siglo XX.

Van Dijk propone entender los temas como "macroproposiciones semánticas": paralelamente a la noción de "proposición”, dichas macroproposiciones están compuestas de participantes (las entidades de las que se habla) y predicados (aquello que se predica o que se dice de los participantes). Para el discurso político propiamente, los participantes pueden estar constituidos por instituciones políticas, organizaciones públicas, poderes, actores y grupos políticos; en conjunto, se definen como "todos aquellos actores que son capaces de contribuir al proceso político" (1999: 41). Los predicados estarán constituidos por los roles de los actores políticos, sus acciones, decisiones y opiniones sobre temas políticos. "[T]ales acciones, decisiones y opiniones tienen una naturaleza general, pública, institucional, oficial y generalmente pertenecen al reino de la gestión pública, la puesta en práctica de políticas, la toma de decisiones, la regulación, el control o sus contrapartes políticas: la protesta, la demostración, la oposición, el desafío, etc.” (1999: 42).

En este artículo, las macroproposiciones semánticas se observan en términos de su codificación lingüística mediante dos tipos de entidades verbales: nominales y predicativas. Las entidades nominales codifican nociones más o menos abstractas, esferas propias de la 
gestión gubernamental, tales como "hacienda", "educación”, "salubridad”, etc. Se verá que la nominalización es un recurso de codificación de alta frecuencia en la titulación y subtitulación; por ejemplo: "Atención de algunos servicios fundamentales que debe prestar el Estado, descuidados por años" (en Trejos 70). Las entidades predicativas codifican acciones concretas que se hicieron, se debieron hacer o se deberán hacer en el futuro. Frente a las entidades nominales, de carácter estático y general, las predicativas muestran poder argumentativo, ya que codifican convicciones concretas del emisor sobre los temas políticos que defiende.

\subsubsection{Superestructuras y esquematización textual}

Los géneros propios del discurso político obedecen a formas esquemáticas compuestas por categorías convencionales que definen la naturaleza del género y la estructura total de su contenido semántico (van Dijk 1999:46). Ejemplos de estas categorías son la argumentación (premisas, conclusión), la narrativa (complicación y resolución), el reporte de sucesos recientes (resumen, noticia), etc.

Una propiedad de estas estructuras esquemáticas es "que pueden lograr significados (globales) parcialmente destacados para razones obvias partidarias. En tanto alguna información sea realzada o no en un titular, un resumen o una conclusión, aquello depende de la manera en que los significados se distribuyan en el discurso" (1999: 46-7).

Hemos dicho ya que el MP, tal como lo hemos caracterizado aquí, constituye un género específico del discurso político, con sus propias dimensiones frente a otros géneros de discurso político (electoral, parlamentario, sindical, etc.), frente a otros subgéneros del discurso presidencial (comunicaciones por los medios, entrevistas, discursos emitidos en distintas configuraciones contextuales, etc.) y frente a los otros tres mensajes de administración, por las condiciones ya señaladas de acumulación y perfectividad.

Finalmente, las características formales, tal como se describen en la siguiente sección, constituyen el esquema discursivo propio del subgénero que aquí se analiza. No es que necesariamente el esquema formal sea exclusivo de este tipo de discurso, pero sí, como se verá, toda manifestación de este tipo de discurso -el MP- se construye sistemáticamente sobre el esquema discursivo descrito.

\subsubsection{Retórica}

Siguiendo a van Dijk, si bien el análisis del léxico en el discurso político ha recibido particular atención en los estudios modernos del discurso, el estudio de la retórica tiene una historia larga que se remonta a los griegos, como es bien sabido. La retórica clásica se desarrolló como el arte de persuadir en el marco de una asamblea política. El estudio de la retórica en el discurso político incluye estudios de las figuras de estilo (metáfora, metonimia), construcciones estilísticas como la hipérbole, en el nivel fonético aliteraciones y rimas, en el sintáctico los paralelismos, etc.

Aunque en el presente artículo no se hace análisis de elementos retóricos específicos, sí se podrá apreciar que la mayoría de los MPs del corpus están elaborados con base en el esquema discursivo descrito ya en la retórica clásica. Para mostrarlo, se presentarán los lineamientos generales del discurso político, tal como los enuncia Aristóteles en su Retórica, la cual será suficiente para caracterizar la estructura formal y semántica de los MPs. 


\section{Análisis de la estructura formal y la tópica del MP}

\subsection{La herencia de la retórica aristotélica}

La retórica clásica provee el marco por excelencia para el análisis del tipo de discurso que nos ocupa. Ya en la Retórica de Aristóteles están establecidas tanto la naturaleza como la temática del discurso político y por ello es desde la retórica que más claramente podemos abocarnos al análisis de este tipo de discurso.

Esta conformación con la retórica clásica se observa desde el primer elemento formal del MP, el título (Tabla 2), en el que se manifiestan sistemáticamente las "tres cosas" de las que consta el discurso, tal como señala Aristóteles en I-33: “... consta de tres cosas el discurso: el que habla, sobre lo que habla y a quién, y el fin se refiere a éste, es decir, al oyente” (1953: 18).

Asimismo, los tres géneros del discurso descritos por Aristóteles se manifiestan en los MPs y sería parte del análisis retórico examinar la composición de los MPs con base en la combinación de los tres géneros:

Forzosamente el oyente es espectador o árbitro, y si árbitro, o bien de cosas sucedidas, o bien de futuras. Hay el que juzga acerca de cosas futuras, como miembro de la asamblea; y hay el que juzga acerca de cosas pasadas, como juez; otro hay que juzga de la habilidad, el espectador, de modo que necesariamente resultan tres géneros de discursos en retórica: deliberativo, judicial y demostrativo (loc. cit.).

Los objetivos del orador, según cada género, son:

- del deliberativo, "lo útil y dañoso" (lo conveniente y lo inconveniente);

- del judicial, "lo justo y lo injusto";

- del demostrativo, "lo honroso y lo feo" (lo noble).

Se desprende de esto que el MP es manifestación del género deliberativo en tanto que el presidente busca convencer a la asamblea de los diputados que empiezan sus labores de proseguir el curso de acción que él como gobernante ha establecido en los últimos cuatro años. Vimos, asimismo, que la Constitución manda al presidente "proponer las medidas que juzgue de importancia para la buena marcha del Gobierno, y el progreso y bienestar de la Nación".

Igualmente, se reconoce que el MP es del género judicial (o forense), ya que tanto la asamblea de los diputados como la ciudadanía (los dos niveles mayoritarios de la categoría receptor) juzgarán al presidente por la labor desempeñada durante su administración y su objetivo fundamental en este discurso es convencerlos de que fue una labor "justa", además de "útil", y finalmente "honrosa".

Por ello el género demostrativo (el que tiene como fin "alabar" o su contrario "vituperar") se hará también manifiesto a lo largo del discurso, como estrategia ornamental para convencer al receptor con respecto a los dos objetivos fundamentales: demostrar la buena labor realizada (objetivo del genero judicial) y persuadir de lo que debe hacerse en el futuro (objetivo del género deliberativo).

Es importante destacar que las líneas temáticas básicas del MP son precisamente las propuestas por Aristóteles como propias del género deliberativo. En I-4, señala que los temas de la oratoria deliberativa son:
a) ingresos fiscales;
b) la guerra y la paz;
c) defensa del país;
d) importaciones y exportaciones;
e) legislación, en relación con las formas de gobierno. 
Las relaciones internacionales, que como se verá, suele ser un tema principal en el MP, Aristóteles las asocia expresamente con los temas b) y d), pero en relación con todos aconseja estudiar los sistemas de otros estados y compararlos con el propio para aprender de la experiencia ajena.

Acerca de todos estos temas, el orador deliberante extrae sus premisas, esto es, "... a partir de qué hay que exhortar y disuadir" (1953: 24).

\subsection{Estructura formal del MP}

El MP se compone formalmente de tres subestructuras: título, marco y discurso.

\subsubsection{Título}

Contiene referencia a "las tres cosas" (ver supra) de que consta el discurso: emisor, mensaje y receptor, más un cuarto elemento contextual fundamental: la fecha de emisión del mensaje.

Lo primero que debe observarse es que el título mismo segmenta el siglo XX en dos mitades, en atención al receptor. Lo que arriba he llamado en términos generales "la asamblea de los diputados" se concreta en el título con la denominación del receptor ya como "Congreso Constitucional", hasta 1947, como "Asamblea Nacional Constituyente", en 1949, o como "Asamblea Legislativa", a partir de $1953^{4}$.

Esta observación es de sumo interés por cuanto ejemplifica claramente aquello a lo que se refieren Halliday y Hasan (1989) cuando dicen: "any piece of text, long or short, spoken or written, will carry with it indications of its context. We only have to hear or read a section of it to know where it comes from. This means that we reconstruct from the text certain aspects of the situation (...). Given the text, we construct the situation from it" (1989: 38). Y también: "the context of situation, the context in which the text unfolds, is encapsulated in the text (...) through a systematic relationship between the social environment on the one hand, and the functional organization of language on the other. If we treat both text and context as semiotic phenomena, as 'modes of meaning', so to speak, we can get from one another in a revealing way" (1989: 11).

Si solo contáramos con la lista de los títulos de los MPs, se nos revelaría que hubo un evento político crucial a mitad del siglo XX, que implicó una reestructuración de la organización política del país; esto se refleja en el cambio de denominación del receptor, de "Congreso" a "Asamblea Legislativa", en la presencia en la mitad del siglo de una "Asamblea Nacional Constituyente", en la caracterización del emisor, no como "Presidente de la República", sino como "Presidente de la Junta de la Segunda República", y finalmente en la fecha de emisión, 16 de enero, que refleja también la ruptura en el proceso regular y cíclico según el cual los MPs se emiten el 1o de mayo.

El corpus, así, queda dividido en dos períodos: 1) 1902-1949, en que el receptor es el Congreso, y por excepción la Asamblea Nacional Constituyente; y 2) 1953-2002, en que el receptor es la Asamblea Legislativa.

Una segunda observación permite distinguir de nuevo dos períodos. Se trata de las fechas de emisión de los Mensajes: observamos que de 1902 a 1914, el intervalo es de 4 años. Sin embargo, el siguiente corresponde a 1916, al que sigue el de 1919, al que a su vez sigue el de 1920. Esta irregularidad en los lapsos muestra que hubo gobiernos de dos, tres y un año respectivamente, lo cual de nuevo refleja una situación política irregular y nos permite segmentar el corpus en dos períodos más: 1) 1902-1920, período que termina con tres administraciones atípicas, y 2) 19241947, período que también termina con una administración atípica (de 3 años). 
Una tercera observación nos permitirá, a partir del título, segmentar el periodo en estudio una vez más. Como puede verse en la Tabla 2, los títulos no presentan mayores variaciones sino hasta 1986, cuando se produce una innovación al introducirse la titulación nominal o predicativa del MP (ver 2.4.2), un recurso temático fundamental, como veremos. Esta variación permite segmentar de nuevo el período en estudio en dos etapas: 1) 1902-1982, con un título genérico, y 2) 1986-2002, con título temático. A partir de 1986, el título genérico pasa a subtitular el MP, lo cual es importante, pues este no puede perder su identificación genérica. Ciertamente, el término "Mensaje" tiene el valor de indicador del género, ya que, como hemos venido señalando, dentro del dominio de las comunicaciones presidenciales, específicamente se refiere a los informes del presidente ante la asamblea de los diputados.

El lector seguramente tiene conocimiento de suficientes elementos contextuales de la historia política nacional para aceptar que el siglo XX puede periodizarse de esta manera; sin embargo, lo que pretendo mostrar aquí es cómo los textos, incluso una simple lista de títulos en su mayoría genéricos, puede dar los elementos necesarios para periodizar sin hacer referencia a los hechos históricos extralingüísticos, revelando así el contexto en que fueron producidos 5 .

Los cuatro períodos propuestos a partir de las variaciones en los títulos de los MPs son:
I Período: de 1902 (Rafael Iglesias) a 1920 (Francisco Aguilar )
II Período:
III Período:
IV Período:
de 1924 (Julio Acosta) a 1949 (José Figueres)
de 1953 (Otilio Ulate) a 1982 (Rodrigo Carazo)
de 1986 (Luis A. Monge) a 2002 (Miguel Á. Rodríguez)

La Tabla II muestra los títulos segmentados en sus componentes. En negrita se destacan aquellos elementos que no aparecen en la posición prevista en los documentos originales (ver Anexo 1. Lista de los Títulos de los MPs del Corpus), con el fin de mostrar que rara vez se altera el orden de los componentes: de las 112 posiciones de la tabla (4 x 28 MPs), solamente 10 elementos no se ubican en la posición esperada.

Tabla 2. Primera subestructura formal: Título

\begin{tabular}{|c|c|c|c|}
\hline Discurso & Emisor & Receptor & Fecha \\
\hline \multicolumn{4}{|l|}{ I Período: $1924-1949$} \\
\hline MENSAJE & $\begin{array}{l}\text { del Señor Presidente de la República } \\
\text { Don Rafael Iglesias }\end{array}$ & $\begin{array}{l}\text { presentado al Congreso } \\
\text { Constitucional }\end{array}$ & el $1^{\circ}$ de mayo de 1902 \\
\hline MENSAJE & $\begin{array}{l}\text { del Señor Presidente de la República } \\
\text { Licenciado Don Ascensión Esquivel }\end{array}$ & $\begin{array}{l}\text { presentado al Congreso } \\
\text { Constitucional }\end{array}$ & el $1^{\circ}$ de mayo de 1906 \\
\hline MENSAJES [sic] & $\begin{array}{l}\text { del Presidente de la República } \\
\text { [Cleto González Víquez] }\end{array}$ & al Congreso Constitucional & 1910 \\
\hline MENSAJE & $\begin{array}{l}\text { del Presidente de la República } \\
\text { [Ricardo Jiménez Oreamuno] }\end{array}$ & al Congreso Constitucional & $1^{\circ}$. de mayo de 1914 \\
\hline $\begin{array}{l}\text { EI Presidente de la } \\
\text { República [Alfredo } \\
\text { González Flores] }\end{array}$ & al Congreso Constitucional & MENSAJE & $1^{\circ}$. de mayo de 1916 \\
\hline MENSAJE & $\begin{array}{l}\text { del Presidente Constitucional } \\
\text { de la República de Costa Rica } \\
\text { Don Federico Tinoco }\end{array}$ & al Congreso Constitucional & el $1^{\circ}$ de mayo de 1919 \\
\hline MENSAJE & $\begin{array}{l}\text { dirigido por el Señor Presidente de } \\
\text { la República, Licdo. Don Francisco } \\
\text { Aguilar Barquero }\end{array}$ & al Congreso Constitucional & $\begin{array}{r}\text { reunido el } \\
1^{\text {o. }} \text { de mayo de } 1920\end{array}$ \\
\hline
\end{tabular}




\begin{tabular}{|c|c|c|c|}
\hline Discurso & Emisor & Receptor & Fecha \\
\hline \multicolumn{4}{|c|}{ II Período: 1924-1949 } \\
\hline MENSAJE & $\begin{array}{l}\text { del Presidente de la República } \\
\text { Don Julio Acosta Garcia }\end{array}$ & $\begin{array}{l}\text { presentado al Congreso } \\
\text { Constitucional }\end{array}$ & $\begin{array}{r}\text { el día } 1^{\circ} \text { de mayo } \\
\text { de } 1924\end{array}$ \\
\hline MENSAJE & $\begin{array}{l}\text { de Don Ricardo Jiménez } \\
\text { Presidente de la República }\end{array}$ & al Congreso Constitucional & $1^{\circ}$. de mayo de 1928 \\
\hline MENSAJE & $\begin{array}{l}\text { del Presidente de la República } \\
\text { [Cleto González Víquez] }\end{array}$ & al Congreso Constitucional & $1^{\circ}$ de mayo de 1932 \\
\hline MENSAJE & de Don Ricardo Jiménez & al Congreso Constitucional & $1^{\circ}$. de mayo de 1936 \\
\hline MENSAJE & del Licenciado Don León Cortés & al Congreso Constitucional & $1^{\circ}$. de mayo de 1940 \\
\hline MENSAJE & $\begin{array}{l}\text { del Señor Presidente de la República, } \\
\text { Doctor Don R. A. Calderón Guardia }\end{array}$ & $\begin{array}{l}\text { presentado al Congreso } \\
\text { Constitucional }\end{array}$ & el $1^{\circ}$. de mayo de 1944 \\
\hline MENSAJE & $\begin{array}{l}\text { del Señor Presidente de la República } \\
\text { Licenciado Don Teodoro Picado }\end{array}$ & $\begin{array}{l}\text { presentado al Congreso } \\
\text { Constitucional }\end{array}$ & el 1o. de mayo de 1947 \\
\hline MENSAJE & presentado a la Asamblea & por Don José Figueres & el 16 de enero de 1949 \\
\hline Presidencial & $\begin{array}{l}\text { Nacional Constituyente de la } \\
\text { Segunda República de Costa Rica }\end{array}$ & $\begin{array}{l}\text { Ferrer Presidente de la } \\
\text { Junta Fundadora de la } \\
\text { Segunda República } \\
\end{array}$ & $\begin{array}{r}\text { San José, Costa Rica } \\
\text { (Palacio Nacional) }\end{array}$ \\
\hline \multicolumn{4}{|c|}{ III Período: 1953-1982 } \\
\hline MENSAJE & $\begin{array}{l}\text { del Señor Presidente Constitucional } \\
\text { de la República Don Otilio Ulate }\end{array}$ & $\begin{array}{l}\text { presentado a la Asamblea } \\
\text { Legislativa }\end{array}$ & el 1o. de mayo de 1953 \\
\hline MENSAJE & $\begin{array}{l}\text { del Señor Presidente de la República } \\
\text { Don José Figueres }\end{array}$ & & $1^{\circ}$ de mayo de 1958 \\
\hline MENSAJE & $\begin{array}{l}\text { del Señor Presidente de la República } \\
\text { Lic. Don Mario Echandi }\end{array}$ & $\begin{array}{l}\text { presentado a la Asamblea } \\
\text { Legislativa }\end{array}$ & el $1^{\circ}$. de mayo de 1962 \\
\hline MENSAJE & $\begin{array}{l}\text { del Señor Presidente Constitucional } \\
\text { de la República de Costa Rica, } \\
\text { Don Francisco J. Orlich }\end{array}$ & & $1^{\circ}$. de mayo de 1966 \\
\hline MENSAJE & $\begin{array}{l}\text { del Presidente de la República } \\
\text { de Costa Rica José Joaquín } \\
\text { Trejos Fernández }\end{array}$ & & $1^{\circ}$. de mayo de 1970 \\
\hline Discurso & $\begin{array}{l}\text { del Señor José Figueres Ferrer } \\
\text { Presidente de la República } \\
\text { de Costa Rica }\end{array}$ & & $1^{\circ}$. de mayo de 1974 \\
\hline $\begin{array}{l}\text { Último Informe } \\
\text { Presidencial de } \\
\text { Mi Administración }\end{array}$ & Presidente Daniel Oduber Quirós & Asamblea Legislativa & $\begin{array}{r}\text { San José, 1o. de mayo } \\
\text { de } 1978\end{array}$ \\
\hline Discurso & $\begin{array}{l}\text { del Señor Presidente de la República } \\
\text { Lic. Rodrigo Carazo }\end{array}$ & a la Asamblea Legislativa & 1o. de mayo 1982 \\
\hline \multicolumn{4}{|c|}{ IV Período: 1986-2002 } \\
\hline $\begin{array}{l}\text { MENSAJE } \\
\text { PRESIDENCIAL } \\
\text { Justicia Social con } \\
\text { Libertad Discurso }\end{array}$ & $\begin{array}{l}\text { del Presidente de la República } \\
\text { Don Luis Alberto Monge }\end{array}$ & & el $1^{\circ}$. de mayo de 1986 \\
\hline $\begin{array}{l}\text { Entrego una Costa } \\
\text { Rica Más Grande } \\
\text { - MENSAJE }\end{array}$ & $\begin{array}{l}\text { del Presidente de la República } \\
\text { Dr. Oscar Arias Sánchez }\end{array}$ & & $1^{\circ}$. de mayo de 1990 \\
\hline
\end{tabular}




\begin{tabular}{|c|c|c|c|}
\hline Discurso & Emisor & Receptor & Fecha \\
\hline $\begin{array}{l}\text { Caminos de } \\
\text { Prosperidad } \\
\text { - MENSAJE }\end{array}$ & $\begin{array}{l}\text { del Señor Presidente de la República } \\
\text { Lic. Rafael Ángel Calderón Fournier }\end{array}$ & $\begin{array}{l}\text { ante la Honorable } \\
\text { Asamblea Legislativa }\end{array}$ & $\begin{array}{l}\text { San José, Costa Rica, } \\
1^{\circ} \text {. de mayo de } 1994\end{array}$ \\
\hline $\begin{array}{l}\text { Una Sociedad } \\
\text { Preparada para el } \\
\text { Futuro - MENSAJE }\end{array}$ & $\begin{array}{l}\text { del Señor Presidente de la República } \\
\text { José María Figueres Olsen, sobre el } \\
\text { Estado de la Nación }\end{array}$ & Asamblea Legislativa & $1^{\circ}$. de mayo de 1998 \\
\hline $\begin{array}{l}\text { Costa Rica } \\
\text { Se Moderniza- } \\
\text { MENSAJE }\end{array}$ & a la Asamblea Legislativa & $\begin{array}{l}\text { del Presidente de la } \\
\text { República, Miguel Ángel } \\
\text { Rodríguez Echeverría }\end{array}$ & $1^{\circ}$. de mayo de 2002 \\
\hline
\end{tabular}

Otros elementos o particularidades relativas al título: González V. 20, además de ser el único que titula MENSAJES, en plural, subtitula con "Mensaje de Administración". Por otra parte, nótese que no todos los MPs estrictamente se identifican con el término "Mensaje": Figueres 74 y Carazo 82 se denominan simplemente "discurso", mientras que Oduber titula "Último Mensaje Presidencial de Mi Administración". Esta titulación atípica parece anticipar la novedad del título temático iniciado con Monge 86. Cabe señalar aquí que el título de Monge "Justicia Social con Libertad" tiene un carácter fuertemente simbólico, ya que enuncia, con tematización inversa, el lema del Partido Social Demócrata, fundado en 1945: "Libertad con Justicia Social" (cp. Monge Alfaro 1974: 285).

Los MPs Figueres 58 y Orlich 66 incluyen la contestación del presidente de la Asamblea Legislativa, de manera que los títulos completos son: "MENSAJE del Señor Presidente de la República Don José Figueres y Contestación del Señor Presidente de la Asamblea Legislativa Dr. Don Álvaro Montero Padilla, $1^{\circ}$ de mayo de 1958” y "MENSAJE del Señor Presidente Constitucional de la República de Costa Rica, Don Francisco J. Orlich y Contestación del Señor Presidente de la Asamblea Legislativa Licenciado Don Rodrigo Carazo Odio, $1^{\circ}$. de mayo de 1966", respectivamente.

Finalmente, cabe agregar que podemos encontrar ya desde el título rasgos que muestran el carácter del emisor, eje estructurante del género deliberativo para Aristóteles (Retórica II-1). Así, algunos emisores se recargan de títulos personales, como en los siguientes ejemplos:

Señor Presidente de la República, Doctor Don R. A. Calderón Guardia

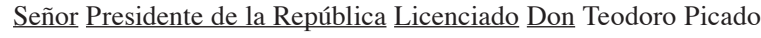

mientras que otros, más bien, excluyen incluso la mención de su nombre:

MENSAJES del Presidente de la República al

Congreso Constitucional -1910

MENSAJE del Presidente de la República al

Congreso Constitucional $-1^{\circ}$. de mayo de 1914

El Presidente de la República al Congreso

Constitucional - MENSAJE - $1^{\circ}$. de mayo de 1916

MENSAJE del Presidente de la República al

Congreso Constitucional - $1^{\circ}$ de mayo de 1932
[Cleto González Víquez]

[Ricardo Jiménez Oreamuno]

[Alfredo González Flores]

[Cleto González Víquez] 
Como se ve, González Víquez no incluye su nombre en el título del MP de ninguna de sus dos administraciones. Por otra parte, como dato adicional, y que puede dar muestras también del carácter del emisor, los cuatro MPs de Calderón Guardia son los únicos originales en la Biblioteca de la Asamblea Legislativa que presentan un encuadernamiento especial, consistente en lujosas cubiertas de cuero repujado.

\subsubsection{Marco}

La subestructura que denomino marco consta de dos elementos: saludo y cierre. Esta subestructura no presenta mayores variaciones a lo largo del período en estudio; sin embargo, puede verse cómo refuerza la segmentación del período propuesta en la subsección anterior.

En cuanto al saludo, típicamente "Señores Diputados", se dan variaciones en el último MP de cada período (penúltimo en el primero, ver Tabla 3): primer período: "Señores Representantes"; segundo período: "Señores Constituyentes"; tercer y cuarto períodos: proliferación de saludos a todos los invitados a la sesión. La divergencia más notable se presenta en el MP Arias 86, en donde el saludo de "Amigas y amigos míos" revela una estrategia de cortesía positiva, de acercamiento e igualdad, según la definición de Brown y Levinson (1987).

Los elementos del cierre son 1) el vocativo de saludo, "Señores Diputados" (solo durante el I período y el primer MP del segundo); 2) nombre impreso (o firma original, particularmente en el I y II períodos), 3) lugar: (Casa Presidencial, en unos pocos casos), San José; y 4) fecha. De los cuatro componentes del cierre pueden aparecer algunos solamente o ninguno, como en Figueres 49 y Arias 90.

Tabla 3. Segunda subestructura formal: Marco (saludo y cierre)

\begin{tabular}{|c|c|c|}
\hline Ident. del MP & Saludo & Cierre \\
\hline \multicolumn{3}{|c|}{ I Período: 1902-1920 } \\
\hline Iglesias 02 & Señores Diputados: & $\begin{array}{l}\text { Señores Diputados: / R.I. / Casa Presidencial. } \\
\text { San José, 1o. de mayo de } 1902\end{array}$ \\
\hline Esquivel 06 & Señores Diputados: & $\begin{array}{l}\text { Señores Diputados: / A.E. / San José, 1o. de } \\
\text { mayo de } 1906\end{array}$ \\
\hline González V.10 & Señores Diputados: & $\begin{array}{l}\text { Señores Diputados. / C.G.V. / San José, 1o. de } \\
\text { mayo de } 1910\end{array}$ \\
\hline Jiménez 14 & Señores Diputados: & $\begin{array}{l}\text { Señores Diputados: / R.J. / San José, 1o. de } \\
\text { mayo de } 1914\end{array}$ \\
\hline González F.16 & Señores Diputados: & Señores Diputados / A.G. \\
\hline Tinoco 19 & Señores Representantes: & $\begin{array}{l}\text { Señores Representantes. / F.T. / Casa } \\
\text { Presidencial. San José, 1o de mayo de } 1919\end{array}$ \\
\hline Aguilar 20 & Señores Diputados: & $\begin{array}{l}\text { Señores Diputados. / F.A.B. / San José, 1o. de } \\
\text { mayo de } 1920\end{array}$ \\
\hline \multicolumn{3}{|c|}{ II Período: 1924-1949 } \\
\hline Acosta 24 & Señores Diputados: & $\begin{array}{l}\text { Señores Diputados. / J.A. / San José, 1o. de } \\
\text { mayo de } 1924\end{array}$ \\
\hline Jiménez 28 & Señores Diputados: & R.J. \\
\hline González V. 32 & Señores Diputados: & C.G.V. / San José, 1o. de mayo de 1932 \\
\hline Jiménez 36 & Señores Diputados: & $\begin{array}{l}\text { R.J. / Casa Presidencial, San José, 1o. de mayo } \\
\text { de } 1932\end{array}$ \\
\hline
\end{tabular}




\begin{tabular}{|c|c|c|}
\hline Ident. del MP & Saludo & Cierre \\
\hline Calderón G. 44 & Señores Diputados: & R.A. C.G. / San José, 1o. de mayo de 1944 \\
\hline Picado 47 & Señores Diputados: & $\begin{array}{r}\text { T.P. / Casa Presidencial, San José, 1o. de mayo } \\
\text { de } 1947\end{array}$ \\
\hline Figueres F. 49 & Señores Constituyentes: & [sin marca de cierre después del epílogo] \\
\hline \multicolumn{3}{|c|}{ III Período: 1953-1982 } \\
\hline Ulate 53 & Señores Diputados: & $\begin{array}{l}\text { O.U. / San José, 1o. de mayo de } 1953 \text { [sigue } \\
\text { Anexo: cuadros y gráficos relativos a las } \\
\text { finanzas públicas] }\end{array}$ \\
\hline Figueres F. 58 & Señores Diputados: & J.F. [después del Anexo: Reforma Constitucional] \\
\hline Echandi 62 & Señores Diputados: & $\begin{array}{l}\text { M.E. / San José, 1o. de mayo de } 1962 \text { [después } \\
\text { del Anexo: Reformas a la Constitución Política] }\end{array}$ \\
\hline Orlich 66 & Señores Diputados: & F. J. O. \\
\hline Trejos 70 & Señores Diputados: & $\begin{array}{l}\text { J.J.T.F. / Presidente de la República / 1o. de } \\
\text { mayo de } 1970\end{array}$ \\
\hline Figueres F. 74 & Señores Diputados: & San José, 1 de mayo de 1974 \\
\hline Oduber 78 & Señores Diputados: & San José, 1o. de mayo de 1978 \\
\hline Carazo 82 & $\begin{array}{l}\text { Señor Presidente de la Asamblea Legislativa } \\
\text { / Señores Diputados / Señor Presidente de la } \\
\text { Corte Suprema de Justicia / Señor Presidente } \\
\text { del Tribunal Supremo de Elecciones / Señores } \\
\text { Magistrados / Señores Ministros y Vice } \\
\text { Ministros de Gobierno / Señores Miembros del } \\
\text { Honorable Cuerpo Diplomático/Excelentísimoy } \\
\text { Reverendísimo Arzobispo de San José / Señores } \\
\text { Contralor y Sub Contralor de la República: }\end{array}$ & $\begin{array}{l}\text { RC/as/nbr } \\
\text { [sigue Anexo: } 4 \text { cuadros de datos relativos a } \\
\text { préstamos] }\end{array}$ \\
\hline \multicolumn{3}{|c|}{ IV Período: $1986-2002$} \\
\hline Monge 86 & Señores diputados: & Muchas Gracias. \\
\hline Arias 90 & Amigas y amigos míos: & [sin marca de cierre después del epílogo] \\
\hline Calderón F. 94 & $\begin{array}{l}\text { Señor Presidente de la Asamblea Legislativa, } \\
\text { Señores Diputados: }\end{array}$ & Muchas gracias. \\
\hline Figueres O. 98 & Señoras diputadas, señores diputados: & Muchas gracias. \\
\hline Rodríguez 02 & $\begin{array}{l}\text { Señor Presidente de la Asamblea Legislativa } \\
\text { y Señoras y Señores Diputados / Señor } \\
\text { Presidente de la Corte Suprema de Justicia } \\
\text { y Señoras y Señores Magistrados / Señor } \\
\text { Presidente del Tribunal Supremo de } \\
\text { Elecciones y Señores Magistrados / Altas } \\
\text { Autoridades del Estado / Señor Arzobispo de } \\
\text { San José / Señoras y señores miembros del } \\
\text { Cuerpo Diplomático / Costarricenses: }\end{array}$ & Muchas gracias. \\
\hline
\end{tabular}

Otros elementos o particularidades relativas al marco: Aunque con muy poca frecuencia, cuatro tipos de elementos pueden aparecer relacionados con las fronteras del discurso como tal:

a) Iniciales: dedicatoria (Figueres 49); epígrafe (Monge 86) 


\begin{abstract}
Dedicatoria: "Edición dedicada, con todo respeto / a los muertos de la Campaña Nacional / 19401949" (Figueres 49).

Epígrafe: "Doy gracias a Dios por haberme concedido el privilegio de nacer en Costa Rica, hoy 1a expresión más alta de 1a democracia latinoamericana y emblema de la paz mundial; doy gracias a Dios por haberme permitido el inmenso honor de servir, como Presidente de la República, al noble pueblo costarricense, pueblo generoso sin límites, trabajador hasta el sacrificio y prudente hasta la sabiduría que marcha hacia la superación integral sin cadenas ni armas" (Monge 86).
\end{abstract}

b) Finales: anexos; se incluyen básicamente dos tipos de anexos: los relativos a reformas constitucionales (Figueres 58; Echandi 62) y los relativos a datos económicos (Ulate 53, Carazo 82). Solo en el caso de Trejos 70 se incluye índice (ver 3.2.3).

Como la totalidad de los elementos que aparecen en el MP, estos también sirven la función retórica de hacer el discurso "digno de fe", mostrar el carácter del emisor y remover las emociones del receptor (Aristóteles, Retórica, II-1).

\title{
3.2.3. Discurso
}

\subsubsection{Unidades temáticas: párrafos y segmentos}

Desde el punto de vista formal, para el análisis de la estructura temática que se propone en las siguientes subsecciones, se observaron dos tipos de unidades: el segmento y el párrafo. El párrafo es la unidad temática mínima considerada en esta investigación; sin embargo en el presente artículo solo nos referiremos al contenido de los segmentos y en algunos casos, a los subsegmentos. Cabe señalar que todos los cuadros de datos numéricos insertos en el discurso se anexan al párrafo temático que los introduce.

El segmento consiste en una secuencia de párrafos que finaliza donde el emisor establece una marca formal de linde. Las marcas suelen ser, en los primeros MPs, el triple asterisco (en González V. 10 se da además una marca de subsegmentación que consiste en un asterisco único).

Todos los MPs presentan segmentaciones $\operatorname{marcadas}^{6}$, que van desde el mencionado asterisco triple hasta la titulación y subtitulación de los segmentos temáticos o secuencias.

I Período: 1902-1920. Segmentación mediante asterisco triple, excepto por González F. 16, que introduce una novedosa y eficiente subtitulación mediante entidades nominales y predicativas (ver 2.4.2 y 3.3.2.1).

II Período: 1924-1949. Segmentación mediante asterisco triple, excepto por Calderón G. 44, que subtitula mediante entidades nominales. Empieza la subsegmentación titulada nominalmente en el campo de obra material (por provincias en Cortés 40 y por tipo de obra en Calderón G. 44).

III Período: 1953-1982. Segmentación mediante asterisco triple. Subsegmentación titulada nominalmente en el campo de obra material por tipo de obra (Ulate 53, Echandi 62).

Trejos 70 introduce la organización del MP en un esquema discursivo jerarquizado y numerado; este es el MP más largo de todo el período, con 43,709 palabras, y el único que cuenta con un índice al final de la edición, que da cuenta precisamente de una minuciosa organización temática.

Se inicia el uso del vocativo "Señores Diputados" al interior del discurso (ver infra) y comienza también el uso sistemático de la subtitulación como recurso no solo de organización 
temática, sino también de argumentación (por ejemplo: "Enriquecimos las cualidades heredadas", segmento final del discurso de Oduber 78).

IV Período: 1986-2002. Se caracteriza por la consolidación del esquema discursivo titulado y subtitulado, con una estructuración temática explícita que funciona como un recurso de argumentación en sí mismo y que contribuye a defender la exposición del emisor. Estas estructuraciones temáticas nos permiten ver la solidez del planteamiento y qué tan airoso salió el emisor de la dispositio ${ }^{7}$.

Uso del vocativo "Señores Diputados" al interior del discurso: Figueres F. 49 introduce un nuevo elemento de segmentación, el vocativo "señores Constituyentes", para marcar el inicio del epílogo; con el mismo fin reaparece en Trejos 70, Figueres 74 y Oduber 78. En Monge 86 se intensifica el uso de este elemento para segmentar, sobre todo en las secuencias inicial y final, y en Calderón F. 94, a todo lo largo del MP. En Figueres O. 98 vuelve a las fronteras del discurso, y en Rodríguez 02 vuelve a distribuirse a lo largo del MP. Esto refleja diferentes estrategias en el manejo de la función conativa frente al receptor del texto. Para mostrar esto, en la lista de tópicos (sección 3.3) se han incluido los vocativos en los puntos en que aparecen en los MPs.

\subsubsection{Secuencias: exordio, cuerpo y epílogo}

Para terminar con la descripción de la estructura formal del MP y enfilar hacia el análisis de su tópica según los cuatro períodos propuestos, me referiré a las secuencias que componen el discurso.

El exordio "[e]s la introducción o puerta de acceso al discurso. (...) Es la parte donde se trata de explicar en síntesis el tema que se va a exponer" (Vilches et al. 2007:34); aquí se establece la perspectiva desde la cual el emisor proyectará su discurso y la plataforma desde la que tratará de captar la benevolencia (captatio benevolentiae) del receptor.

Formalmente, el exordio sigue inmediatamente al saludo y termina con la primera marca de segmentación. Solo por excepción el MP carece de exordio; es el caso de Jiménez 36, que inicia de la siguiente manera: Las rentas produjeron en el año de $1935 ф 27.166,764.86$. Rebasaron la estimación del Presupuesto en
$\varnothing 2.853,764.86$. Los vaticinios de los pesimistas fallaron.

Es evidente que la alternativa de prescindir del exordio constituye una poderosa estrategia argumentativa, al arrancar el discurso con la presentación de datos directos y desnudos como en este caso.

El cuerpo se compone de todos los segmentos comprendidos entre la primera marca de segmentación posterior al saludo y la última marca de segmentación previa al cierre.

En la codificación de los textos realizada en esta investigación, las tres secuencias discursivas fueron etiquetadas de la siguiente manera:

$\begin{array}{ll}\text { Exordio: } & \mathrm{S} 1=\text { segmento } 1 \\ \text { Cuerpo: } & \mathrm{S} 2 \ldots \mathrm{Sn} \\ \text { Epílogo: } & \mathrm{Sn}+1\end{array}$

Por lo general tanto exordio como epílogo constan de un solo segmento, mientras que el cuerpo consta de un número variable de segmentos que a menudo se componen de subsegmentos. La subsegmentación suele alcanzar dos niveles (aunque alcanza hasta cuatro en Trejos 70); los subsegmentos se etiquetaron así: (S1, primer nivel) - S1.1, S1.2 ... S1.n. 
En la Retórica (III-19), Aristóteles termina refiriéndose al epílogo y contrastándolo con el exordio de la siguiente manera: "En el exordio, pues, conviene exponer el asunto para que no pase inadvertido sobre qué es el juicio, aquí en el epílogo hay que decir los puntos principales que han servido para la demostración. El principio será decir que ha hecho lo que había prometido, de manera que hay que decir de qué se trata y el por qué" (1953: 229). Se verá que para las secuencias exordio y epílogo, por lo general no he consignado el contenido, por cuanto las más de las veces se trata de contenidos muy formulaicos (agradecimientos, buenos deseos, etc) ${ }^{8}$.

\subsection{La tópica del MP}

\subsubsection{Preliminares: tema y tópico del discurso}

Givón (1984) se refiere a la estructura jerárquica del discurso como parte de su estructura temática:

\footnotetext{
Multi-propositional discourse is not merely a concatenation ('chain') of atomic propositions. Rather, it tends to display a more elaborate, commonly hierarchic structure. Typically, with the narrative serving for the moment as the prototype for discourse, the overall story is divided into chapters, chapters into episodes, episodes into macro-paragraphs and these last into smaller thematic paragraphs. The lastmentioned are made up of complex sentences and/or, finally, propositions ('clauses'). This hierarchic array is part of the thematic structure of discourse. (1984: 137).
}

Por su parte, Grimes (1975) concibe la estructura temática de un texto dentro de un subsistema textual que denomina perspectiva (staging). La perspectiva se refiere al punto de vista desde el cual cada sección del discurso se le presenta al oyente. "Normally [staging relationships] make one part of a stretch of discourse the THEME or TOPIC and relate everything else to it" (1975: 113). La perspectiva funciona en varios niveles:

a) la estructura temática que crea el escenario para el discurso total;

b) la estructura temática involucrada en las cláusulas;

c) la estructura temática a niveles intermedios: oraciones, párrafos, etc.

"Every clause, sentence, paragraph, episode and discourse is organized around a particular element that is taken as point of departure. It is as though the speaker presents what he wants to say from a particular perspective" (1975: 323)

La estructura temática, entonces, es según Grimes la manera en que el hablante provee una perspectiva particular a lo que dice. Es parte del sistema de cohesión de un texto y tiene que ver con cómo los diferentes elementos se organizan en el desarrollo del discurso. Opera en varios niveles: cláusulas, párrafos y discurso en su conjunto. Tal como señala Givón, puede proporcionar un medio para segmentar un texto en párrafos; un cambio de tema usualmente marca lindes entre párrafos.

Hemos visto que Grimes utiliza los términos theme y topic indistintamente. Aquí nos detendremos para aclarar estos conceptos y quedarnos con el término de tópica para referirnos, con van Dijk, al conjunto de temas recurrentes en un determinado tipo de discurso.

En la sección anterior segmentamos el texto solamente por las marcas formales que originalmente encontramos en los MPs, esto es, tal como los emisores delimitaron segmentos y subsegmentos en el texto; hasta este momento no hemos entrado a determinar la estructura conceptual y cómo ésta se manifiesta a través de la estructura temática de los textos.

Sin embargo, para determinar lo que Brown y Yule (1993) llaman un fragmento discursivo, no siempre se dispone de marcadores que claramente identifiquen su principio 
y su fin. Por ello es necesario remitirse a la noción de tópico; pero también surge el problema de determinar qué es un tópico del discurso.

Una forma de abordar el problema es distinguiendo entre un tópico oracional (o tema en la lingüística sistémica funcional de Halliday), un tópico del discurso y un tópico del hablante.

a) El tópico oracional o tema se refiere al constituyente inicial de una oración. La operación de colocar un constituyente típicamente no inicial en la primera posición de la oración se llama topicalización o tematización. Esta noción no se aplicará en el análisis de la tópica del MP.

b) El tópico del discurso, de acuerdo con Keenan y Schieffelin (1976, citado en Brown y Yule 1993), puede definirse como una proposición, una única oración que resume la "cuestión de interés inmediato". Otros (Bransford y Johnson 1973, citado en Brown y Yule 1993) han propuesto que el título de un texto constituye su tópico.

La noción tradicional de tópico como "aquello sobre lo que se habla o escribe" es considerada por Brown y Yule como una noción preteórica e intuitiva; sin embargo, es la que más nos acerca a lo que aquí denominamos como la tópica del discurso: aquello sobre lo que se está hablando.

Una forma de caracterizar sistemáticamente la noción es delimitando lo que Brown y Yule llaman el marco del tópico, el cual definen como un marco contextual o conjunto de rasgos activados del contexto: los rasgos que se reflejan directamente en el texto y a los que se recurre para su interpretación. Un marco del tópico podría incluir: el género al que pertenece el texto, el contenido de la secuencia del acto (objetos y acciones), tiempo y lugar (escenario, ambientación), motivos del hablante (por qué el hablante dijo lo que dijo en determinado momento del discurso).

Puede observarse con claridad que nuestra propia noción de marco, descrita en la subsección 3.2.2 como subcomponente de la estructura formal del MP, precisamente activa los rasgos del contexto necesarios para determinar que el contenido del discurso corresponde al MP: por una parte, está dirigido a los diputados (saludo: Señores Diputados) y por otra, el emisor y la fecha quedan establecidos en el cierre: firma o nombre del presidente, 1o. de mayo de (año correspondiente).

c) Finalmente, Brown y Yule defienden una tercera noción de tópico: el tópico del hablante, que se define como "aquello de lo que creo que estamos hablando"; para Brown y Yule, es importante comprender que son los hablantes y no los textos los que tienen tópicos. Sin embargo, esta noción prueba ser más útil en el análisis de discursos interactivos como la entrevista, el debate, etc., que en el género que aquí nos ocupa.

En este artículo nos interesa la noción de tópico como contenido semántico del discurso. En este mismo sentido, Wardhaugh (1985) señala que cualquier cosa que uno diga como participante en un acto discursivo debe ser tópica, en el sentido de que debe ser relevante o al menos estar conectada con aquello de lo que se habla. Aun cuando el tópico no se ha hecho explícito, los hablantes sabrán de qué se trata mediante un proceso de inferencia. Los participantes infieren de las diferentes contribuciones y sus participaciones forman acumulaciones alrededor del tópico. El foco de esas acumulaciones será el tópico del discurso.

Para observar la tópica de cada MP, en las próximas secciones se consignan las secuencias mayores (exordio, cuerpo y epílogo) y los segmentos que componen el cuerpo del discurso. No se incluye la subsegmentación, excepto en casos que requieran comentario o bien cuando los emisores la hayan marcado explícitamente mediante subtitulación.

Los tópicos aparecen codificados, como se dijo en 2.4.2, mediante entidades (sintagmas) nominales y entidades predicativas (cláusulas). Aparecen dentro de paréntesis cuadrados cuando 
el texto original no los presenta explícitamente (mediante subtitulación). En tales casos, para codificar el tópico se han escogido las expresiones más utilizadas por el emisor; por ejemplo, el tópico educación, puede aparecer codificado como "instrucción pública", "enseñanza pública", o "educación pública".

Además se incluye la siguiente información: El número de segmentos (nS) (tal como aparecen segmentados los textos originales); el número de párrafos (nP) y el número total de palabras (pals) de cada MP.

\title{
3.3.2. Tópica por $M P$
}

\subsubsection{Primer período: 1902-1920}

\author{
1) Iglesias 02: 8S - 41P - 3684pals \\ S1 [Exordio] \\ S2 [Relaciones internacionales] \\ S3 [Canal interoceánico a través de CA que EEUU planea construir] \\ S4 [Instrucción pública] \\ S5 [Situación económica] \\ S6 [Ejecución de obras públicas] \\ S7 [Relaciones entre la Iglesia y el Estado] \\ S8 [Epílogo]
}

\section{2) Esquivel 06: 20S - 52P - 6496pals}

S1 [Exordio]

S2 [Campaña electoral reciente]

S3 [Actitud del presidente Esquivel en el proceso político reciente]

S4 [La tendencia subversiva derivó en rebelión armada]

S5 [Consecuencia: suspensión de las garantías individuales]

S6 [Relaciones exteriores]

S7 [Actividades y reuniones internacionales]

S8 [Laudo sobre frontera con Panamá]

S9 [Poder Judicial]

S10 [Nuevo Código de Procedimientos Penales]

S11 [Relaciones Iglesia - Estado]

S12 [Servicios de beneficencia]

S13 [Enseñanza pública]

S14 [Desarrollo de la riqueza nacional y obras públicas]

S15 [Ferrocarril al Pacífico]

S16 [Obras públicas: puentes y caminos, cárcel pública y otros]

S17 [Situación económica: finanzas públicas]

S18 [Deuda exterior]

S19 [Departamento de Guerra: ausencia de actividad militar]

S20 [Epílogo]

\section{3) González V 10: 17S - 290P - 16464pals}

S1 [Exordio]

S2 [Relaciones internacionales]

S3 [Exportación de banano y situación de la actividad bananera ]

S4 [Exportación de cacao y situación de la actividad cacaotera]

S5 [Otras exportaciones: cueros, maderas, concha perla, oro y plata]

S6 [Exportación de caucho; la actividad cauchera como impulso para la zona norte; necesidad de vías de transporte] 
S7 [Resumen de exportaciones e importaciones]

S8 [Importaciones de gran interés para la agricultura y la industria]

S9 [Movimiento fiscal]

S10 [Salubridad pública]

S11 [Grandes obras públicas]

S12 [Relaciones Iglesia - Estado]

S13 [Asuntos judiciales]

S14 [Instrucción pública]

S15 [Milicia y policía]

S16 [Sismos del mes de abril]

S17 [Epílogo]

En este caso, en el texto se da segmentación y subsegmentación (mediante asterisco triple y asterisco simple respectivamente, en el texto original); pero el uso de estos recursos revela problemas de organización temática. Por evidentes razones de espacio, no se incluye aquí la subsegmentación completa; sin embargo, véase el segmento 2, que ejemplifica este problema de asistematicidad. Mientras que la segmentación muestra las relaciones internacionales como tema central, se observa la inclusión del tema independiente de la situación económica, de modo que la exportación de café queda incluida en ese segmento. Como puede verse, en los siguientes segmentos se retoma el tema de las exportaciones:

S2 [Relaciones internacionales]

S2.1 [Generalidades. Congreso Panamericano]

S2.2 [Cuarta Conferencia Sanitaria Internacional de las Repúblicas Americanas]

S2.3 [Conflicto armado en Nicaragua; problema en el río San juan]

S2.4 [Segunda Conferencia de Delegados Centroamericanos en San Salvador. Seis convenciones suscritas]

S2.5 [Laudo Loubet sobre frontera con Panamá]

S2.6 [Solución del reclamo Mc. Connell sobre cultivo de Gandoca]

S2.7 [Construcción finalizada del Palacio de la Paz]

S2.8 [Becas del Gobierno de El Salvador para estudiar en su Colegio Nacional de Agricultura]

S2.9 [Situación económica]

S2.10 [Exportación de café. Problemas en la actividad cafetalera, reflexiones y sugerencias]

S3 [Exportación de banano y situación de la actividad bananera ]

S4 [Exportación de cacao y situación de la actividad cacaotera]

S5 [Otras exportaciones: cueros, maderas, concha perla, oro y plata]

\section{4) Jiménez 14: 6S - 412P - 1140pals}

S1 [Exordio - Asuntos internacionales]

S2 [Principal asunto nacional: elecciones recientes y la actitud del Presidente Jiménez ante ellas]

S3 [Tesoro público: rentas fiscales y salidas ordinarias]

S4 [Renuencia a dar sugerencias al próximo gobierno excepto por poner atención a la región noreste del país]

S5 [Remisión a los informes de las Secretarías de Estado]

S6 [Fuerza pública: guarniciones y policía. Ascensos de militares]

\section{5) González F 16: 96S - 203P - 23742pals}

\section{S1 [Exordio]}

S2 Relaciones internacionales. Tratado canalero

S3 Laudo White

S4 Congresos financieros

S5 Cordialidad centroamericana

S6 Lealtad y disciplina del ejército

S7 Labores de Instrucción Pública

S8 Concurso de los padres de familia en la labor educativa

S9 Deficiencias de la ley de educación

S10 Aumento de la población escolar. Carencia de locales 
S11 Enseñanza industrial

S12 Escuela Normal

S13 Enseñanza secundaria

S14 Labor sanitaria

S15 Labores de Fomento

S16 Gastos en reparaciones de edificios

S17 Gastos en carreteras, caminos y puentes

S18 Trabajo de reos

S19 Ferrocarril al Pacífico

S20 Explotación de bosques nacionales

S21 HACIENDA PUBLICA. Dificultades comerciales

S22 Renta de Aduanas. Causas de su descenso

S23 Reducción de gastos. Desequilibrio de los presupuestos

S24 Pago puntual a nuestros acreedores

S25 Mejora de la situación económica del país

S26 Pago parcial de sueldos

S27 Las finanzas necesitan mejorarse

S28 Los servicios del Estado debe pagarlos el país

S29 El país debe mantener su independencia

S30 La mayoría del país apoya la reforma

S31 Enseñanzas de la guerra europea

S32 La reforma tributaria propuesta no ha sido combatida en el fondo

S33 Las rentas menores de $ф 1000$ quedan libres de impuesto

S34 Debe facilitarse la implantación de la reforma

S35 Impuesto progresivo sobre tierras incultas

S36 Inconsulta política agraria

S37 Pretensiones inmorales de los especuladores

S38 Conflicto de derechos

S39 El aumento de población ante el acaparamiento de tierras

S40 El impuesto progresivo y el catastro aclararán la situación del problema agrario

S41 Importancia social del monopolio de licores

S42 Los derechos de Aduana como medida social y proteccionista

S43 Carestía de la vida. Derechos aduaneros

S44 Injustificada protección a los molinos de trigo y a los ingenios de azúcar

S45 Insuficiencia de los sueldos actuales

S46 El jornal del peón es bajo

S47 Hay que mejorar la vida del trabajador

S48 Más médicos. Medicinas libres

S49 Carestía de la vida debida a los malos caminos

S50 La reforma bancaria es indispensable para abaratar la vida

S51 Falta de crédito barato para el pequeño agricultor

S52 Cajas rurales de crédito

S53 Sección Hipotecaria para el pequeño propietario

S54 La ley de Prenda Agraria facilita el uso del crédito

S55 La carestía de la vida se combate con facilidades de crédito

S56 Combatir el alza del cambio es combatir la carestía de la vida

S57 Crisis monetaria

S58 Balance comercial favorable

S59 Contrato de giros por $\$ 500,000$

S60 Balance internacional de pagos

S61 Otros pagos en el exterior fuera del valor de la importación

S62 Empréstito francés

S63 El interés no bajó 
S64 El empréstito francés falseó la situación

S65 Disminución del stock de oro. Especulación en cambios

S66 Situación sana hoy, peligrosa en el futuro

S67 Dividendos que se van

S68 Primas de aseguros

S69 Peligro para el futuro

S70 La reforma bancaria prevendrá el peligro

S71 Ventajas de la emisión centralizada

S72 Inconvenientes de la emisión múltiple

S73 Quiebra del Banco Comercial

S74 Defectos de la Ley de Bancos

S75 Bases para un Banco Nacional

S76 Sin estabilidad en los cambios no hay negocio seguro

S77 Sin reforma fiscal sería ilusoria la bancaria

S78 El momento actual es oportuno para la reforma bancaria

S79 La situación es sana en el fondo

S80 La emisión debe separarse de los negocios bancarios

S81 La importación debe restringirse

S82 La emisión debe servir para fomentar la producción

S83 Reforma aduanera para disminuir la importación

S84 La sanidad de la moneda atrae los capitales

S85 Debe nacionalizarse el aseguro

S86 Inseguridad de los asegurados

S87 La necesidad social del aseguro

S88 ¿Convienen las grandes Compañías extranjeras?

S89 Ni abundan ni faltan brazos

S90 Colonización interior espontánea

S91 Fracaso de la colonización artificial

S92 Hay capitales nacionales

S93 Si se dan concesiones exíjase el pago de lo que valen

S94 Ventajas y peligros de capital extranjero

S95 Nada se hace con variar el valor del colón

S96 [Epílogo:] Las dificultades pueden vencerse

Cabe ejemplificar con este MP la combinación de entidades nominales y predicativas y la fuerza retórica que introduce la intercalación de ambos recursos de codificación, como habíamos señalado en 2.4.2:

S83 Reforma aduanera para disminuir la importación

Nominal

S84 La sanidad de la moneda atrae los capitales

Predicativa

S85 Debe nacionalizarse el aseguro

Predicativa

S86 Inseguridad de los asegurados

Nominal

S87 La necesidad social del aseguro

Nominal

S88 ¿Convienen las grandes Compañías extranjeras?

Predicativa

S89 Ni abundan ni faltan brazos

Predicativa

\section{6) Tinoco 19: 10S - 116P - 10226pals}

\section{S1 [Exordio]}

S2 Relaciones exteriores

S3 Gobernación y Policía

S4 Hacienda y Comercio

S5 Fomento

S6 Instrucción Pública

S7 Guerra y Marina

S8 Justicia y Gracia 
S9 Culto y Beneficencia

S10 [Epílogo]

\section{7) Aguilar 20: 7S - 33P - 3740pals}

\section{S1 [Exordio]}

S2 [Referencia a los hechos que llevaron a Aguilar a la Presidencia; corto gobierno de transición]

S3 [Convocatoria a elecciones y restitución de la Constitución del 71; algunas acciones del Gobierno Provisional]

S4 [Instrucción pública]

S5 [Situación del Banco Internacional de Costa Rica; giros irregulares durante el gobierno de Tinoco]

S6 [Crédito exterior]

S7 [Epílogo]

El Cuadro 3 muestra una matriz de los tópicos tratados en el primer período. Los numerales muestran el orden en que aparecen en cada MP.

Cuadro 3. Tópica del I Período 1902-1920

\begin{tabular}{|c|c|c|c|c|c|c|c|}
\hline & Iglesias & Esquivel & González V & Jiménez & González F & Tinoco & Aguilar \\
\hline $\begin{array}{l}\text { Asuntos políticos } \\
\text { / electorales recientes }\end{array}$ & & $\mathrm{I}$ & & II & & & I \\
\hline $\begin{array}{l}\text { Relaciones } \\
\text { internacionales }\end{array}$ & I & II & I & I & I & I & \\
\hline $\begin{array}{l}\text { Asuntos económicos: } \\
\text { Hacienda y } \\
\text { comercio }\end{array}$ & III & VIII & II & III & VI & III & III \\
\hline $\begin{array}{l}\text { Instrucción / } \\
\text { Educación }\end{array}$ & II & VI & VII & & III & V & II \\
\hline $\begin{array}{l}\text { Obras públicas / } \\
\text { Fomento }\end{array}$ & IV & VII & IV & & V & IV & \\
\hline $\begin{array}{l}\text { Relaciones } \\
\text { Iglesia-Estado / } \\
\text { Beneficiencia }\end{array}$ & V & $\begin{array}{l}\text { IV } \\
\text { V }\end{array}$ & V & & & VIII & \\
\hline Policía / Milicia & & IX & VIII & IV & II & II & \\
\hline Asuntos judiciales & & III & VI & & & VII & \\
\hline Salubridad / Higiene & & & III & & IV & & \\
\hline Guerra y Marina & & & & & & VI & \\
\hline
\end{tabular}

Aunque "Guerra y Marina" es un tema tratado solamente por Tinoco, se incluye por cuanto constituye una de las ocho secciones temáticas de su MP y no cabría suprimirla.

\subsubsection{Segundo período: $1924-1949$}

\section{8) Acosta 24: 12S - 94P - 9028pals}

S1 [Exordio - Pasada campaña electoral]

S2 [Relaciones exteriores]

S3 [Secretaría de Fomento; remisión al informe de esa secretaría]

S4 [Educación Pública]

S5 [Hacienda Pública; ejercicio fiscal; Caja de Conversión]

S6 [Gobernación; municipalidades; homenaje a García Flamenco y a Arias Durán; Ley de Juegos, Higiene y Salud Pública] S7 [Administración de justicia]

S8 [Rescisión del contrato con un capitán de la Guardia Civil Española, necesidad de crear una Guardia Civil en el país] 
S9 [Necrología de los expresidentes Esquivel e Iglesias]

S10 [Temblor del 4 de marzo; nombramiento de una Junta Nacional de Socorros; ayudas externas]

S11 [Agradecimiento a los guardianes de las armas]

S12 [Epílogo]

\section{9) Jiménez 28: 19S - 25P - 5687pals}

S1 [Rentas, egresos, comercio internacional]

S2 [Exportación de café; exportación y situación de la actividad bananera; exportación de cacao]

S3 [Incremento del tráfico del Ferrocarril al Pacífico; necesidad de sustraer su administración de la política]

S4 [Necesidad del régimen del servicio civil: pruebas de competencia y ascensos por méritos comprobados en el servicio]

S5 [Fábrica Nacional de Licores]

S7 [Excelente gestión del Secretario de Hacienda]

S8 [Necesidad de modernizar el Ministerio Público]

S9 [Necesidad de modernizar el Registro de la Propiedad y completar el plano catastral de la República]

S10 [Necesidad de una ley forestal]

S11 [Emisión de bonos]

S12 [Caja de conversión; deudas del Estado]

S13 [Ley sobre Accidentes de Trabajo]

S14 [Registro Cívico: "Sin un buen padrón de sufragantes no puede haber elecciones satisfactorias"]

S15 [Necesidad de que se requiera saber leer y escribir para poder votar]

S16 [Necesidad de una reforma constitucional respecto a la designación de los sustitutos del Presidente]

S18 [Escuela de Artes y Oficios]

S19 [Epílogo]

\section{0) González V 32: 11S - 111P - 11398pals}

S1 [Exordio]

S2 [Relaciones exteriores]

S3 [Reforma al Código de Procedimientos Civiles]

S4 [Elecciones nacionales; actitud del Presidente González V.; levantamiento armado frustrado; a partir del P17: finanzas públicas]

S5 [Crisis económica agravada por caída de la libra esterlina; dependencia del café; necesidad de producir trigo; otras actividades económicas]

S6 [Tesoro Público: entradas, egresos, deuda interna, deuda externa]

S7 [Problemas y reflexiones sobre la deuda externa]

S8 [Mejoras al Puerto del Pacífico]

S9 [Generación de empleo para los obreros sin trabajo]

S10 [Educación Pública]

S11 [Salubridad Pública]

S12 [Epílogo (sin marca)]

\section{1) Jiménez 36: 7S - 39P - 4819pals}

S1 [Finanzas públicas]

S2 [Presupuestos municipales y su efecto en el tesoro nacional]

S3 [Exportaciones e importaciones; cambio monetario]

S4 [Buen ambiente internacional para los productos nacionales]

S5 [Beneficio de la baja de intereses y los arreglos de las deudas hipotecarias]

S6 [Epílogo: Optimismo sobre la situación nacional e internacional. Opinión sobre reformas constitucionales]

S7 [Entrega del informe de la Secretaría de Hacienda]

\section{2) Cortés 40: 21S - 134P - 9677pals}

S1 [Exordio - Campaña electoral - Necesidad de una Ley de Elecciones]

S2 [Honra en memoria de Monseñor Castro Jiménez]

S3 [Relaciones internacionales]

S4 [Convenio con Nicaragua para la canalización del río San Juan]

S5 [A raíz de la guerra europea, creación de la Conferencia de Ministros de Relaciones Exteriores de América; Comité Consultivo Económico Financiero Interamericano] 
S6 [Participación del Secretario de Hacienda en la Conferencia de Guatemala]

S7 [Gobernación, Municipalidades, Policía]

S8 [Registro Civil y Cívico]

S9 [Sugerencia de levantar el censo general de la población]

S10 [Hacienda pública: rentas, egresos, deuda externa, deuda interna, Tributación Directa]

S11 [Enseñanza pública]

S12 [Higiene pública]

S13 [Cartera de Fomento: Ferrocarril Eléctrico al Pacífico; remisión a la memoria de la Secretaría de Fomento]

S14 [Sumas invertidas y obras desarrolladas por provincia durante el período fiscal que se reseña]

S15 [Construcción de barrios obreros]

S16 [Escuela de Agricultura]

S17 [Desarrollo de la zona sur gracias a la contratación de la Compañía Bananera]

S18 [Apoyo económico para Policía, Cuarteles, Banda Militares]

S19 [Agradecimiento a la milicia, encargada de mantener el orden público]

S20 [Reforma al artículo 52 sobre educación, cuya dirección pasó de las municipalidades al poder ejecutivo]

S21 [Epílogo]

\section{3) Calderón G 44: 11S - 58P - 6665pals}

\section{S1 [Exordio]}

S2 Relaciones Exteriores

S3 Gobernación y Policía

S4 Trabajo y Previsión Social

S5 Hacienda y Comercio

S6 Educación Pública

S7 Fomento

S8 Agricultura

S9 Salubridad Pública y Protección Social

S10 Seguridad Pública

S11 [Epílogo]

\section{4) Picado 47: 12S - 108P - 13591pals}

S1 [Exordio]

S2 [Relaciones internacionales]

S3 [Justicia; relaciones con el Poder Judicial; relaciones con la Iglesia]

S4 [Labores de la Secretaría de Gobernación: Código Electoral, Municipalidades, Registro de la Propiedad; aviación civil]

S5 [Gasto público, situación fiscal]

S6 [Educación]

S7 [Secretaría de Fomento]

S8 [Salubridad Pública]

S9 [Secretaría de Agricultura]

S10 [Agricultura, ganadería, industrias]

S11 [Secretaría de Trabajo]

S12 [Epílogo - orden público - próxima campaña política]

\section{5) Figueres F 49: 11S - 41P - 4609pals}

S1 [Exordio]

S2 [Propósito: definir la situación política y crear una nueva Constitución; antecedentes 1940-44]

S3 [Antecedentes 1944-48]

S4 [Un nuevo orden jurídico e institucional. El Pacto Ulate-Figueres]

S5 [Tareas de la Junta Fundadora de la Segunda República]

S6 [Las cuatro orientaciones o aspiraciones generales de la Segunda República]

S7 [Primera orientación/aspiración: Restablecimiento de la moral]

S8 [Segunda orientación/aspiración: Introducción de la técnica en la administración y eliminación de la politiquería] 
S9 [Tercera orientación/aspiración: Progreso social sin comunismo]

S10 [Cuarta orientación/aspiración: Mayor conciencia de solidaridad con los otros pueblos del mundo, especialmente de América]

S11 [Epílogo] [Vocat:] Señores Constituyentes:

Siguiendo el mismo estilo de matriz tópica del primer período, en el Cuadro 4 se observan los nuevos temas que surgen este segundo período:

\section{Cuadro 4. Tópica del II Período 1924-1949}

\begin{tabular}{|c|c|c|c|c|c|c|c|c|}
\hline & Acosta & Jiménez & González V & Jiménez & Cortés & Calderón G & Picado & Figueres $\mathrm{F}$ \\
\hline $\begin{array}{l}\text { Asuntos políticos } \\
\text { / electorales recientes }\end{array}$ & I & & III & & I & & & I \\
\hline $\begin{array}{l}\text { Relaciones } \\
\text { internacionales }\end{array}$ & II & & I & & III & I & I & \\
\hline $\begin{array}{l}\text { Asuntos económicos: } \\
\text { Hacienda y } \\
\text { comercio }\end{array}$ & V & I & IV & I & VIII & $\mathrm{V}$ & VII & \\
\hline Educación & IV & & VII & & IX & VI & VIII & \\
\hline $\begin{array}{l}\text { Obras públicas / } \\
\text { Fomento }\end{array}$ & III & & $\mathrm{V}$ & & XI & VII & IX & \\
\hline Policía / Milicia & $\mathrm{X}$ & & & & $\begin{array}{c}\text { VI } \\
\text { XIII }\end{array}$ & III & & \\
\hline Asuntos judiciales & IX & III & II & & & & II & \\
\hline $\begin{array}{l}\text { Salubridad / Protección } \\
\text { social }\end{array}$ & VIII & & VIII & & $\mathrm{X}$ & IX & $\mathrm{X}$ & \\
\hline Gobernación & VI & & & & IV & II & III & \\
\hline Municipalidades & VII & & & II & V & & $\mathrm{V}$ & \\
\hline Servicio Civil & & II & & & & & & \\
\hline Registro de la Propiedad & & IV & & & & & VI & \\
\hline Registro Cívico / Civil & & VI & & & VII & & & \\
\hline $\begin{array}{l}\text { Ley de Elecciones } \\
\text { / Código Electoral }\end{array}$ & & & & & II & & IV & \\
\hline Agricultura & & & & & XII & VIII & $\mathrm{XI}$ & \\
\hline Trabajo & & $\mathrm{V}$ & VI & & & IV & XII & \\
\hline Seguridad Pública & & & & & & $\mathrm{X}$ & XIII & \\
\hline Reformas Constitucionales & & & & III & XIV & & & \\
\hline
\end{tabular}

Con respecto al período anterior, desaparece el tópico "Relaciones Iglesia-Estado / Beneficiencia", mientras que se introduce una serie de temas relativos a la organización institucional del país, en particular Gobernación, Municipalidades, Registro Civil, Registro de la Propiedad, etc. Fundamental es aquí la introducción de los temas de las garantías electorales, el trabajo y la seguridad social como grandes tópicos por desarrollar durante la segunda mitad del siglo XX.

Son atípicos los mensajes de Jiménez, más orientados a las necesidades del país con respecto a ciertos temas concretos, que a describir detalladamente la labor del gobierno, excepto en lo que concierne a los asuntos económicos. Igualmente, es atípico el MP de Figueres; su exposición se refiere al trabajo de la Junta Fundadora de la Segunda República en sus 18 meses de gobierno y, más relevante, a las cuatro orientaciones estratégicas que deberán dirigir el desarrollo político de la segunda república. 


\subsubsection{Tercer período: $1953-1982$}

\section{6) Ulate 53: 15S - 189P - 15179pals}

S1 [Exordio1]

S2 [Exordio2]

S3 [Defensa de la democracia en contra del comunismo. Ejemplos del campo de la salud y otros varios]

S4 [Trabajo]

S5 [Ministerio de Agricultura e Industrias]

S6 [Educación]

S7 [Obras Públicas: Período de un año a que se contrae el Mensaje del $1^{\circ}$ de mayo de 1953 (subsegmentación por Departamentos: construcciones, puentes, obras hidráulicas, caminos públicos, caminos vecinales; movimiento económico; planteles, compras, Instituto Geográfico Nacional, aeropuertos, Ferrocarril Eléctrico al Pacífico, Ferrocarril del Norte; promedio de gastos; Carretera interamericana )]

S8 [Situación del sistema monetario, divisas, exportaciones e importaciones]

S9 [Plan de desarrollo económico; situación de la economía; política fiscal]

S10 [Relaciones internacionales]

S11 [Problema sobre el costo de la vida y el gasto familiar en lotería]

S12 [Problema de los patentados de licores]

S13 [Recomendación de construir estadios y plazas para deporte]

S14 [Reconocimiento a los diputados que terminan su período]

S15 [Epílogo]

$\mathrm{S}$ [Anexo: cuadros y gráficos relativos a las finanzas públicas]

\section{7) Figueres F58: 7S - 100P - 4451pals}

S1 [Exordio]

S2 [Finanzas públicas]

S3 [Problemas pendientes]

S4 [Necesidad del Instituto de Tierras y Colonias y de una legislación agraria general. Planes para la televisión]

S5 [Relaciones políticas entre gobierno y oposición]

S6 [Reflexiones a diez años de la guerra civil]

S7 [Tribunal Supremo de Elecciones y depuración del Padrón Electoral - Necesidad de la deuda política Política exterior - Epílogo]

S10 [Anexo: reforma constitucional]

\section{8) Echandi 62: 10S - 91P - 11118pals}

S1 [Exordio]

S2 [Obras públicas (subsegmentación por: edificios, carreteras, puentes, cañerías)]

S3 [Justicia]

S4 [Trabajo]

S5 [Caja Costarricense del Seguro Social. Instituto Nacional de Vivienda y Urbanismo]

S6 [Salubridad Pública]

S7 [Educación Pública]

S8 [Situación económica]

S9 [Epílogo]

S10 [Anexo:] Reformas a la Constitución Política

\section{9) Orlich 66: 40S - 104P - 10427pals}

S1 [Exordio]

S2 [Continuación del exordio; saludo a los invitados a la sesión y a los diputados salientes]

S3 [Respeto al Poder Judicial y al Tribunal Supremo de Elecciones]

S4 [Contraloría de la Nación]

S5 [Ministerio de Gobernación, Policía, Justicia y Gracia y Ministerio de Seguridad Pública]

S6 [Procuraduría General de la República]

S7 [Ministerio de Seguridad Pública]

S8 [Reconocimiento a los cuerpos de la fuerza pública] 
S9 [Reflexión sobre la pasada campaña electoral]

S10 [Homenaje al cuerpo de funcionarios de la Administración Pública; Servicio Civil. P25: Relaciones exteriores]

S11 [Hacienda: organización de las finanzas públicas y promoción de la producción nacional]

S12 [Construcción de la infraestructura para la economía nacional. Papel del Ministerio de Transportes]

S13 [Transportes: el Plan Vial; Carretera Interamericana]

S14 [Carretera a Limón]

S15 [Mantenimiento de carreteras nacionales y regionales]

S16 [Empréstitos negociados para carreteras]

S17 [Planes para la construcción de un puerto en Moín]

S18 [Inicio de un canal interior de Moín a Colorado]

S19 [Ferrocarril al Atlántico]

S20 [Ferrocarril Eléctrico al Pacífico]

S21 [Instituto Costarricense de Electricidad]

S22 [Telecomunicaciones. Necesidad del crédito extranjero o nacional para el desarrollo del país]

S23 [Necesidad de la intervención del estado en favor de grupos en desventaja]

S24 [Sin dejar de ser un agrícola, Costa Rica debe promover la producción industrial]

S25 [Producción agrícola y ganadera: Ministerio de Agricultura y Ganadería; Consejo Nacional de Producción]

S26 [Sector manufacturero]

S27 [Proceso integracionista centroamericano. Necesidad de la acción conjunta entre los sectores público y privado]

S28 [Necesidad de explotar la industria del turismo]

S29 [Necesidad de la planificación para el desarrollo económico]

S30 [Justicia social: participación equitativa del ingreso nacional. Relaciones obrero-patronales. Ministerio de Trabajo]

S31 [Patronato Nacional de la Infancia]

S32 [Caja Costarricense de Seguro Social]

S33 [Cooperación de la CCSS al ICE y al ITCO. Ministerio de Salubridad Pública. Servicio Nacional de

Acueductos y Alcantarillados]

S34 [Plan de Acueductos en las Zonas Rurales]

S35 [Instituto Nacional de Vivienda y Urbanismo]

S36 [Programas de desarrollo de la comunidad]

S37 [Educación]

S38 [Educación Vocacional: creación del Instituto Nacional de Aprendizaje]

S39 [Cultura: Dirección General de Artes y Letras del Ministerio de Educación]

S40 [Movimiento Nacional de Juventudes. Epílogo]

\section{0) Trejos 70: 5S - 446P - 43709pals}

\section{S1 [Exordio]}

S2 Capítulo I Sobre el Estado Político de la República

S2.1 I.1 La Paz

[Introducción]

$\mathrm{S} 2.1 .2$

La Paz y el Cambio Social. Auge Económico y Adversidades de la Naturaleza

$\mathrm{S} 2.1 .3$

La Paz y la Fuerza Pública. El Proceso Electoral

S2.1.4

Paz y Armonía en las Relaciones Internacionales

$\mathrm{S} 2.1 .5$

Un Solo Frente, de Índole Nacional, en las Relaciones Internacionales

S2.1.6

Respeto y Amor al Prójimo

$\mathrm{S} 2.2$

$\mathrm{S} 2.2 .1$

$\mathrm{S} 2.2 .2$

$\mathrm{S} 2.2 .3$

$\mathrm{S} 2.3$

I. 2 Reformas a la Constitución Política de la República

[Introducción]

Otras Importantes Reformas Constitucionales

Revisión Total de la Constitución Política

$\mathrm{S} 2.4$

$\mathrm{S} 2.4 .1$

$\mathrm{S} 2.4 .2$

$\mathrm{S} 2.4 .3$

I.3 La experiencia en un Poder Ejecutivo cuya política no cuenta con el respaldo de una mayoría parlamentaria

I.4 Desarrollo Económico

[Introducción]

I.4.1 El Producto Nacional

I.4.2 Inversión 
S2.4.4

S2.4.5

S2.4.5.1

S2.4.5.2

S2.4.6

S2.4.7

S2.4.8

S2.5

S2.5.1

S2.5.2

S2.5.3

S2.5.4

S2.5.5

S2.5.5.1

S2.5.5.2

S2.5.5.3

S2.5.5.4

S2.5.5.5

S2.5.5.6

S2.5.5.7

S2.5.5.8

S2.5.6

S2.5.7

S2.5.8

S2.5.9

S3

S3.1

S3.2

S3.3

S3.3.1

S3.3.2

S3.3.2.1

S3.3.2.2

S3.3.3

S3.3.4

S3.3.5

S3.3.6

S3.3.7

S3.3.8

S3.3.9

S3.3.10

S3.4

S3.4.1

S3.4.2

S3.4.3

S3.4.4

S3.5

S3.5.1

S3.5.2

S3.5.3

S3.5.4

S3.5.5

S3.5.6

S3.6
I.4.3 Exportaciones e Importaciones

I.4.4 La Moneda

[Introducción]

Deuda Externa

I.4.5 Crédito

I.4.6 La Hacienda Pública

I.4.7 Otros Comentarios y Datos Sobre el Crecimiento de la Economía

I.5 Desarrollo Social

[Introducción]

I.5.1 Crecimiento Demográfico y Educativo

I.5.2 Salud

I.5.3 Vivienda

I.5.4 Desarrollo Agrario

I.5.4.1 Descentralización de los Servicios para los Agricultores

I.5.4.2 Mercadeo de los Productos Agropecuarios

I.5.4.3 Desarrollo Agrícola y Educación

I.5.4.4 Estudio Global del Sector Agropecuario

I.5.4.5 Desarrollo Agrario y Cooperativas

I.5.4.6 Seguro de Cosechas

I.5.4.7 Ley Forestal

I.5.4.8 Tenencia de la Tierra

I.5.5 Seguridad Social

I.5.6 Esfuerzo Propio, Solidaridad Social y Desarrollo de las Comunidades

I.5.7 Banco Popular y de Desarrollo Comunal

I.5.8 Reforma Penitenciaria

Capítulo II Diversos Asuntos de la Administración

II.1 Planificación

II.2 Relaciones Internacionales y Comercio de Nuestros Productos

II.3 Transportes

[Introducción]

II.3.1 Carretera Interamericana

[Introducción]

Carretera El Coco-San Ramón

II.3.2 "Planes Viales"

II.3.3 El Segundo Plan Vial de Caminos Vecinales

II.3.4 Carretera de Primera Calidad de Siquirres a Limón

II.3.5 El Plan de Mantenimiento de Carreteras y Caminos

II.3.6 Muelles en Puerto Limón

II.3.7 Aeropuerto para Avionetas y Aeropuerto de El Coco

II.3.8 Obras Publicas Realizadas Mediante Planes Cooperativos con Organismos Locales

II.3.9 Asuntos Varios

II.4 Reformas Administrativas en Varios Ministerios de Gobierno

II.4.1 Salubridad Pública

II.4.2 Hacienda

II.4.3 Gobernación

II.4.4 Reorganización de Ministerios al Término de la Administración

II.5 Atención de algunos servicios fundamentales que debe prestar el Estado, descuidados por años [Introducción]

II.5.1 Seguridad y Protección para los Ciudadanos

II.5.2 Registro Público

II.5.3 Registro de Prendas

II.5.4 Imprenta Nacional

II.5.5 Correos

II.6 Construcciones Escolares 
S3.7

S4

S4.1

S4.2

S4.2.1

S4.2.2

S4.2.3

S4.2.4

$\mathrm{S} 4.3$

S4. 4

S4.4.1

S4.4.2

S4.4.2.1

S4.4.2.2

S4.4.2.3

S4.4.2.4

S4.4.3

S4.4.4

S5

S5.1

S1.2

$\mathrm{S}$
II.7 Dirección de Bienestar Social

Capítulo III Recomendaciones adicionales sobre medidas importantes para la buena marcha del Gobierno y el progreso y bienestar de la Nación

[Introducción]

III.1 Centro Cívico

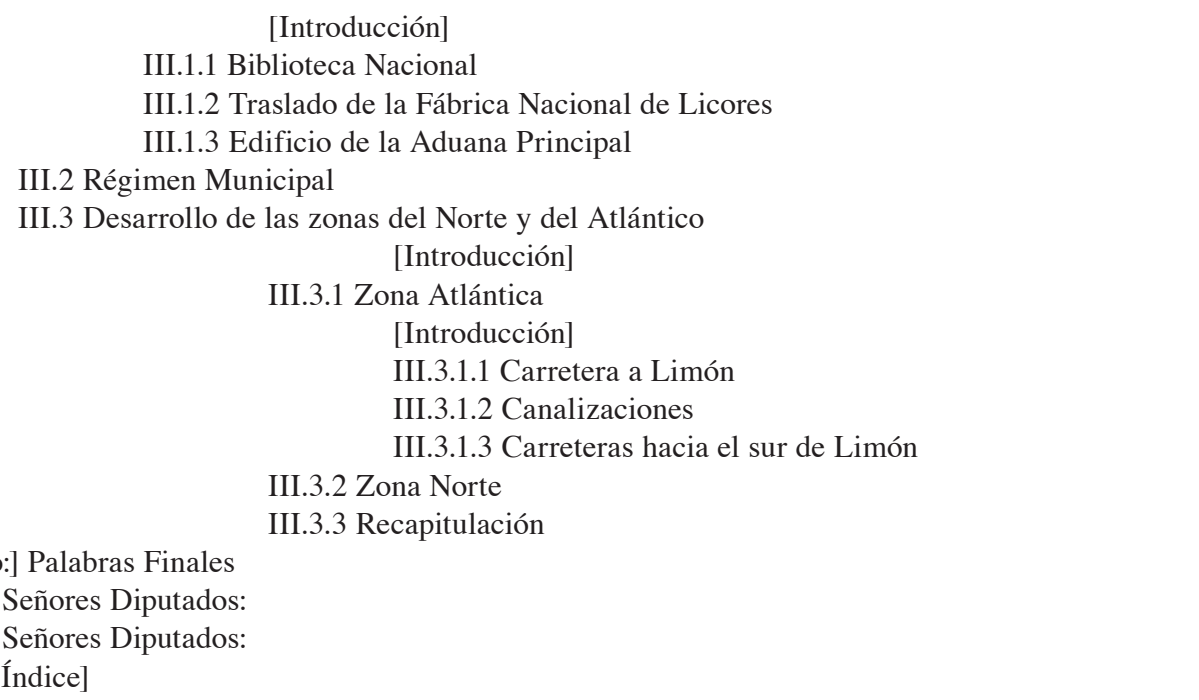

III.1.1 Biblioteca Nacional

III.1.2 Traslado de la Fábrica Nacional de Licores

III.1.3 Edificio de la Aduana Principal

\section{1) Figueres F74: 6S - 23P - 810pals}

S1 [Exordio]

S2 [Exordio cont.] [Vocat:] Señores diputados:

S3 [Situación económica]

S4 [Transformación hacia la era industrial]

S5 [Necesidad de aprobar el Proyecto de Asignación Familiar]

S6 [Epílogo] [Vocat:] Señores diputados:

\section{2) Oduber 78: 12S - 84P - 7135pals}

\section{S1 [Exordio]}

S2 Bajo el signo de la crisis

S3 El primer requisito: la paz política

S4 La crisis de los alimentos

S5 La crisis energética

S6 La crisis financiera

S7 El prestigio internacional

S8 Avances espectaculares en salud

S9 Logros educativos impresionantes

S10 Revolución nutritiva

S11 Enriquecimos las cualidades heredadas

S12 [Epílogo] [Vocat:] Señores Diputados

\section{3) Carazo 82: 16S - 184P - 17888pals}

S1 [Exordio]

S2 Desarrollo Regional

S3 Agricultura

S3.1 Estímulo y no congelación de precios

S3.2 Espectacular producción de granos básicos

S3.3 Después de 50 años de promesas: Proyecto de Riego Arenal Tempisque

S3.4 Incremento de la producción y apertura de nuevos mercados

S3.5 Duplicación de exportaciones de productos no tradicionales 
S3.6

S3.7

S4

S5

S5.1

S5.2

S5.3

S5.4

S5.5

S5.6

S5.7

S5.8

S5.9

S5.10

S5.11

S5.12

S5.13

P5.14

S5.15

S5.16

S5.17

S5.18

S5.19
Compra de Fertica

Más títulos de propiedad en cuatro años que en cualquier otra Administración

Pesca

Obras en el Campo Social

[Introducción]

Educación: reconocimiento internacional

Tecnología

Promoción cultural y deportiva

Salud: un proceso ininterrumpido y ejemplar de varios gobiernos.

Un orgullo nacional: la universalización de los servicios de salud y de los riesgos del trabajo VIVIENDA: 50,202 soluciones. Plan Regional Metropolitano

Agua potable: 835 sistemas de acueducto y alcantarillado. 312 acueductos rurales.

La Familia

Menores de Edad

Políticas de población: respeto a la dignidad humana

Programa de parques populares y recreación familiar

Parques nacionales: de 181.945 hectáreas a 418.268 hectáreas. Un puesto de avanzada en el mundo

Planificación, regionalización y autogestión

Reforma Administrativa

Sistema Penitenciario Nacional

Registro Nacional

Procuraduría General de la República

Política laboral, paz social, diálogo permanente, disminución de huelgas, revisión de la legislación social, guarderías.

Política Internacional Dinámica

[Creación de la Universidad para la Paz]

Obra Material

Guardia Civil y Guardia de Asistencia Rural. Imparcialidad Política

Una obra gigantesca y el boicot contra lo positivo

Fin del subdesarrollo portuario en Costa Rica

Energía y Comunicaciones

Duplicación en estos 4 años de la capacidad hidroeléctrica del país

Superación de todos los índices anteriores

En estos cuatro años se construyó el ferrocarril eléctrico más largo del país

Dos oleoductos y modernización de RECOPE

Compra de Petróleo Mediante Acuerdos de Gobierno a Gobierno

[El gobierno anterior suspendió inexplicablemente el contrato petrolero con Venezuela]

Programa México-Venezuela de Cooperación Energética

Reducción del $18 \%$ en consumo de petróleo

Conversión de motores

Recursos carboníferos

Control de la explotación del oro

Alcohol carburante

Déficit Fiscal y Deuda Pública

[Efecto del alto déficit fiscal y la deuda pública]

Compromisos sin financiar

Apego a los Hechos

[Las crisis nacional y mundial exigen medidas impopulares, "fieles no al aplauso o a un

falso populismo, sino al mantenimiento de las instituciones y a la preservación de la paz social: fieles a la felicidad de un pueblo que es eterno y que debe superarse sin límites, pese a las dificultades".]

Vertiginoso descenso del valor de las exportaciones y aumento del petróleo

Flotación de la Moneda 
JARA: Discurso presidencial costarricense: estructura formal y tópica del último mensaje...

$\mathrm{S} 12.1$

$\mathrm{S} 12.2$

$\mathrm{S} 12.3$

S13

S13.1

S13.2

S13.3

S13.4

S13.5

S14

S14.1

S14.2

S14.3

S15

S16

S16.1

S16.2

$\mathrm{S}$

[Efecto de la injusticia internacional. Reflexión y satisfacción sobre las medidas económicas tomadas]

Obstáculos Legislativos a Proyectos de Ley favorables al país

Reformas estructurales

Ingresos Suficientes

[Ingresos fiscales satisfactorios; aprobación del "paquete tributario"; gastos]

Esfuerzo notable en 1981 a la contención de gastos

Disminución del déficit económico en $₫ 1.692$ millones

Disminución de la emisión monetaria

Inflación y depresión

[Epílogo:] Consideraciones Finales

[Salimos adelante sin ayuda financiera internacional]

Respeto y dignidad

Justicia social internacional y el plan del Presidente Reagan para Centro América y el Caribe

Paz con Libertad

Apoyo Irrestricto al Próximo Gobierno

[Solicitud del apoyo de los costarricenses al próximo gobierno]

Unidad en lo esencial o pacto social

[Anexo: 4 cuadros de datos relativos a préstamos]

Cuadro 5. Tópica del III Período 1953-1982

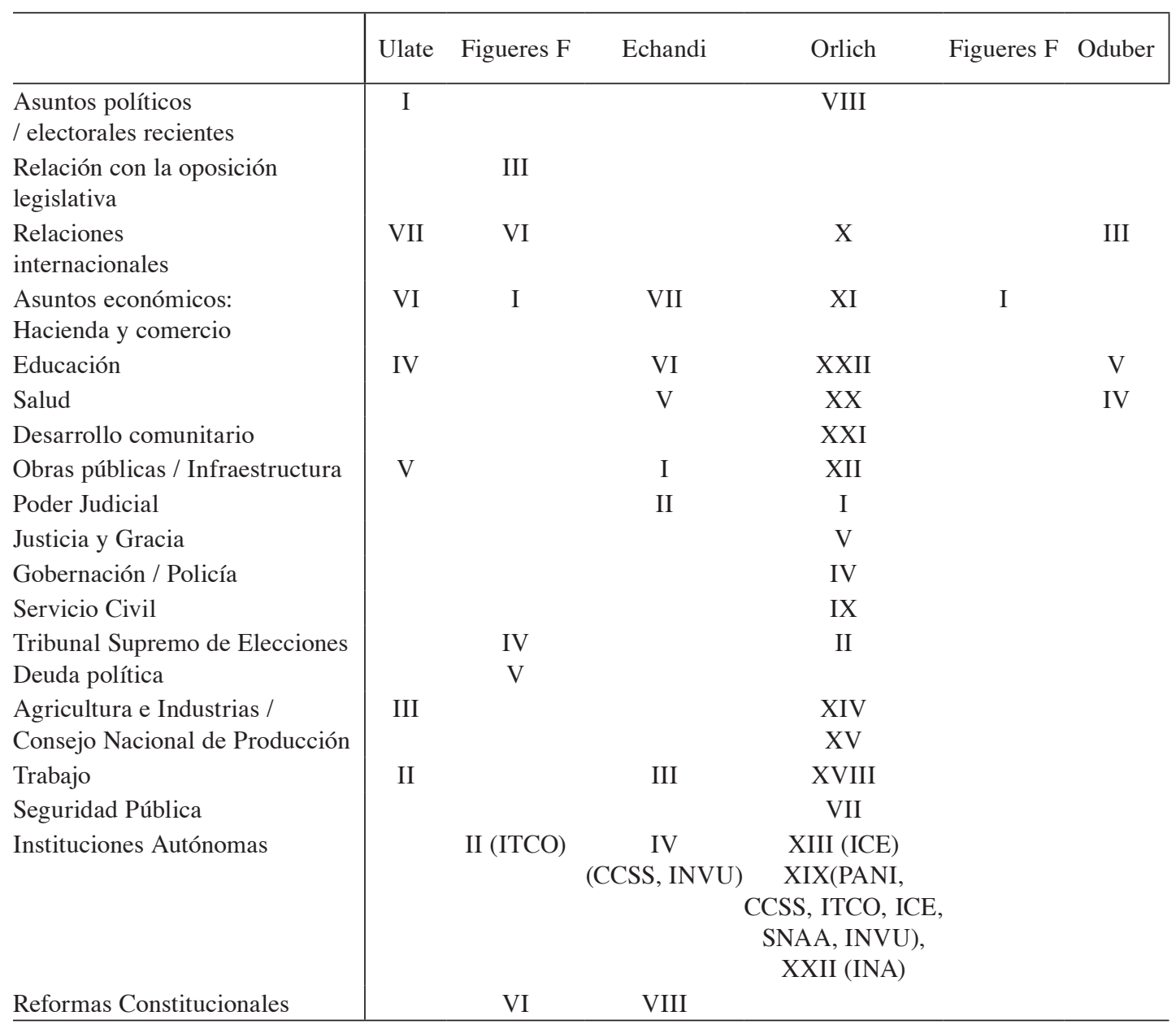


En este tercer período es donde se diversifican los tópicos, ya que se incrementan las instituciones del estado y por ende se hace más complejo el discurso desde el punto de vista temático. Algunos temas no llegan a constituir tópicos porque no son recurrentes; sin embargo, es importante destacar, al menos, en el caso de Orlich 66 los temas (en diversos puntos del discurso) de la Contraloría, la Procuraduría General de la República, la integración centroamericana, el turismo y la cultura (en la Dirección de Artes y Letras, Ministerio de Educación, ya que no se había creado el Ministerio de Cultura); en el caso de Figueres F 74, los temas de la transformación del país hacia la era industrial y el Proyecto de Asignaciones Familiares (temas segundo y tercero); y en el caso de Oduber 78, los temas de la paz (ya tematizado por Trejos, como se ve infra), las diversas crisis (de alimentos, energética y financiera) y la nutrición (temas primero, segundo y sexto).

La organización temática que presentan Trejos 70 y Carazo 82 no permite adecuarla a la matriz sin hacerla excesivamente compleja. Por ello he preferido mostrar sintéticamente el esquema temático de cada uno de estos MPs, incluyendo solamente la segmentación y la subsegmentación de primer nivel en el caso de Trejos, y la segmentación en el caso de Carazo:

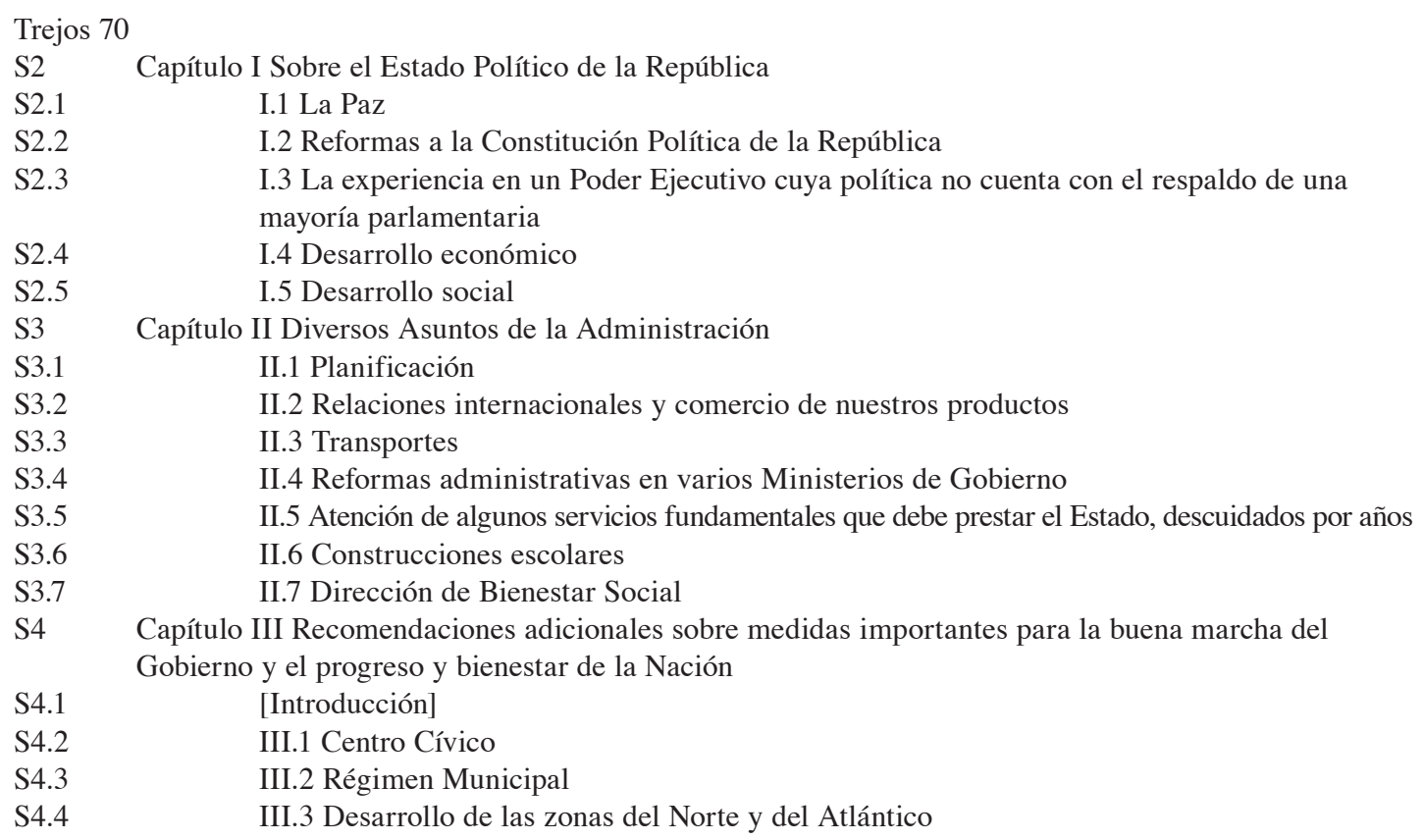

Carazo 82

S2 Desarrollo regional

S3 Agricultura

S4 Pesca

S5 Obras en el campo social

S6 Política internacional dinámica

S7 Obra material

S8 Energía y comunicaciones

S9 Compra de petróleo mediante acuerdos de gobierno a gobierno

S10 Déficit fiscal y deuda publica

S11 Apego a los hechos

S12 Flotación de la moneda 
S13 Ingresos suficientes

S14 Consideraciones finales

S15 Paz con libertad

S16 Apoyo irrestricto al próximo gobierno

\subsubsection{Cuarto período: $1986-2002$}

\section{4) Monge 86: 32S - 87P - 7976pals. Título: Justicia social con libertad EPÍGRAFE \\ S1 [Exordio]}

S2 [Vocat:] Señores diputados: [1982: Plan Nacional de Emergencia de los primeros cien días]

S3 [Vocat:] Señores Diputados: [1982: la peor crisis económica, moral y política de los últimos 40 años en Costa Rica]

S4 Unidad nacional frente a la crisis

S5 La crítica situación de mayo de 1982

S6 Los objetivos de nuestra Política Económica

S7 Una línea de acción realista y pragmática

S8 Un esfuerzo sobrehumano y heroico

S9 Decidido apoyo al sector de comercio exterior

S10 El nuevo modelo de desarrollo

S11 El plan de compensación social

S12 Justicia social con libertad

S13 La democratización de la economía

S14 La Ley de Asociaciones Solidaristas

S15 La cooperativa es fuente de riqueza y solidaridad humana

S16 Un país de propietarios y no de proletarios

S17 Superadas todas las metas de salud en América Latina

S18 Varilla y cemento

S19 Solución integral al abastecimiento de agua en el área metropolitana

S20 Energía y luz para los campos de Costa Rica

S21 Volvamos a la Tierra

S22 La situación agropecuaria

S23 La agricultura de riego

S24 Año Internacional de la Paz

[Vocat:] Señores Diputados:

S25 La fuerza espiritual de Costa Rica

S26 La neutralidad de Costa Rica

S27 La neutralidad como instrumento jurídico

S28 Costa Rica está contra la guerra

[Vocat:] Señores Diputados:

S29 El compromiso democrático de Costa Rica

S30 Una nueva relación con Europa

S31 El prestigio internacional de Costa Rica

S32 [Epílogo:] Diálogo y consenso nacional

[Vocat:] Señores Diputados:

[Vocat:] Señores Diputados:

[Vocat:] Señores Diputados:

[Vocat:] Señores Diputados:

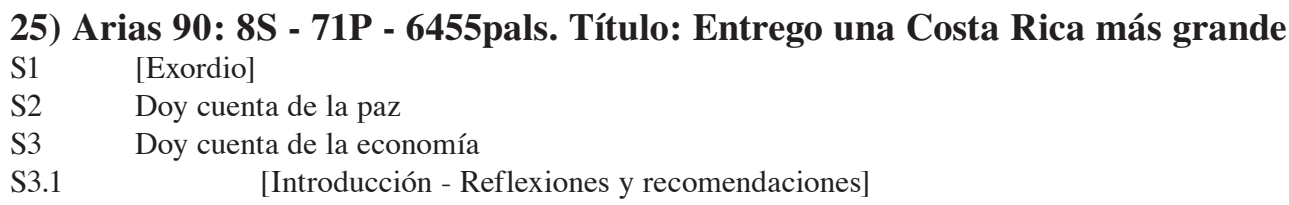




$\begin{array}{lc}\text { S3.2 } & \text { Agricultura } \\ \text { S3.3 } & \text { Turismo } \\ \text { S3.4 } & \text { Caminos y carreteras } \\ \text { S3.5 } & \text { Deuda externa } \\ \text { S3.6 } & \text { Economía pequeña } \\ \text { S4 } & \text { Doy cuenta de la vivienda } \\ \text { S5 } & \text { Doy cuenta de la educación } \\ \text { S5.1 } & \text { [Introducción - Principales logros] } \\ \text { S5.2 } & \text { Ciencia y Tecnología } \\ \text { S6 } & \text { Doy cuenta de la salud } \\ \text { S7 } & \text { Doy cuenta del medio ambiente } \\ \text { S7.1 } & \text { [Introducción - Principales logros] } \\ \text { S7.2 } & \text { Energía y Desarrollo } \\ \text { S7.3 } & \text { Telecomunicaciones y desarrollo } \\ \text { S7.4 } & \text { Calidad de vida } \\ \text { S8 } & \text { [Epílogo] [Vocat:] Amigas y amigos míos: }\end{array}$

26) Calderón F 94: 6S - 233P - 9723pals. Título: Caminos de Prosperidad

S1 [Exordio - Apoyo al proyecto de reforma del artículo 50 de la Constitución Política]

S2 I. Crecimiento Económico: [Vocat:] Señores Diputados:

S3 II. Estabilidad Económica: [Vocat:] Señores Diputados:

S4 III. Equidad:

S4.1 [Vocat:] Señores Diputados: [“durante nuestra Administración se redujo la población que vive en pobreza y en extrema pobreza, a los niveles más bajos de nuestra historia"]

S4.2 [Vocat:] Señores Diputados: [Reforma Económica - creación del Bono Gratuito de ViviendaProyectos de la Primera Dama - Salud - Educación - Garantías Sociales y Código de Trabajo - Justicia]

S4.3 [Vocat:] Señores Diputados: [Cultura, juventud, deporte, mujer y familia]

[Vocat:] Señores Diputados: [Área ambiental]

[Vocat:] Señores Diputados: [Ministerio de Gobernación; Ministerio de Seguridad]

[Vocat:] Señores Diputados: [Política exterior]

V. [Epílogo.] Reflexiones finales

["He mencionado algunas de nuestras victorias durante estos 4 años. El tiempo no nos permite incluir a todas"]

[Vocat:] Honorables Diputados: [“Gloria Bejarano ha sido indispensable para mí y para el Presidente de este país"]

En este MP se ve claramente cómo la subsegmentación se hace por medio del vocativo "Señores Diputados".

\section{7) Figueres O 98: 3S (11Subs) - 78P - 8982pals. Título: Una sociedad preparada para el futuro \\ S1 I. Un Tiempo de Reencuentro con el Camino de las Oportunidades \\ S1.1 \\ S 1.2 \\ S1.3 \\ S2.4 \\ 1. Un momento propicio para la reflexión nacional [Vocat:] Señoras diputadas, señores diputados: \\ 2. Un pueblo especial que construyó un camino de oportunidades \\ 3. Con la crisis de los ochentas se truncó el camino de las oportunidades \\ 4. Nos propusimos reencontrar el camino de oportunidades}

$\mathrm{S} 2$

S2.1

$\mathrm{S} 2.2$

$\mathrm{S} 2.3$

$\mathrm{S} 2.4$

II. El Trecho Avanzado hacia la Costa Rica de Oportunidades [Además de los informes de cada dependencia del gobierno, se entrega a la Asamblea un documento del Ministerio de Planificación Nacional donde se evalúa el cumplimiento de las principales acciones del Programa de Gobierno.]

1. El eje económico

2. El eje social

3. El eje ambiental 
S3

S3.1

S 3.2

S3.3

III. Costa Rica Es Más Gobernable y Más Sostenible

1. Reencontramos el camino del bienestar para todos

[Vocat:] Señoras diputadas y señores diputados:

[Vocat:] Señoras diputadas y señores diputados:

2. La Asamblea Legislativa ha sido un promotor esencial de los cambios

3. [Epílogo:] Mi profundo agradecimiento al pueblo costarricense [Vocat:]

Queridas y queridos costarricenses.

\section{8) Rodríguez 02: 3S - 115P - 11664pals. Título: Costa Rica se moderniza}

S1 [Exordio - nuevo modelo de desarrollo humano]

S2 El Trabajo de los Costarricenses

S3 Continuemos Trabajando

S3.1 [Necesidades para el futuro: educación, infraestructura física y telecomunicaciones, reducción de las tasas de interés y de la inflación, aprobación del Tratado de Libre Comercio con Estados Unidos]

S3.2 [Vocat:] Señoras y señores diputados, costarricenses: [Reconocimiento al aporte de gobiernos anteriores. Medidas más importantes para el futuro: reforma fiscal, acceso al crédito, reforma laboral. El "Triángulo de la Solidaridad"]

S3.3 [Vocat:] Señoras y señores diputados: [Beneficios del Tratado de Libre Comercio con Estados Unidos y Centroamérica]

S3.4 [Epílogo] [Vocat:] Señoras y señores diputados, costarricenses:

Cuadro 6. Tópica del IV Período 1986-2002

\begin{tabular}{|c|c|c|c|c|c|}
\hline & Monge & Arias & Calderón F & Figueres $\mathbf{O}$ & Rodríguez \\
\hline $\begin{array}{l}\text { Título } \\
\text { del MP }\end{array}$ & $\begin{array}{c}\text { Justicia social } \\
\text { con libertad }\end{array}$ & $\begin{array}{l}\text { Entrego una } \\
\text { Costa Rica } \\
\text { más grande }\end{array}$ & $\begin{array}{l}\text { Caminos de } \\
\text { prosperidad }\end{array}$ & $\begin{array}{l}\text { Una sociedad } \\
\text { preparada para } \\
\text { el futuro }\end{array}$ & $\begin{array}{c}\text { Costa Rica } \\
\text { se moderniza }\end{array}$ \\
\hline $\begin{array}{l}\text { Conceptos } \\
\text { claves }\end{array}$ & $\begin{array}{l}\text { * Crisis del } 82 \\
* \text { Unidad nacional } \\
* \text { Comercio exterior } \\
\text { * Plan de compen- } \\
\text { sación social: } \\
\text { Justicia social } \\
\text { con libertad } \\
\text { * Democratización } \\
\text { económica } \\
* \text { Asociaciones } \\
\text { solidaristas / } \\
\text { cooperativas } \\
* \text { Salud } \\
* \text { Obra pública, } \\
\text { agua, luz y energía } \\
* \text { Agricultura } \\
* \text { Año Internacional } \\
\text { de la Paz } \\
* \text { Neutralidad } \\
* \text { Prestigio } \\
\text { internacional }\end{array}$ & $\begin{array}{l}\text { * Paz } \\
\text { * Economía: } \\
\text { Agricultura } \\
\text { Turismo } \\
\text { Carreteras } \\
\text { Deuda externa } \\
\text { * Vivienda } \\
\text { * Educación } \\
\text { * Ciencia y } \\
\text { tecnología } \\
\text { * Salud } \\
\text { * Ambiente: } \\
\text { Energía } \\
\text { Telecomunicaciones } \\
\text { Calidad de Vida }\end{array}$ & $\begin{array}{l}\text { * Crecimiento } \\
\text { económico } \\
\text { * Estabilidad económica } \\
\text { * Equidad } \\
\text { * Reforma económica } \\
\text { * Bono Gratuito de la } \\
\text { Vivienda } \\
\text { * Proyectos de la } \\
\text { Primera Dama } \\
\text { * Salud } \\
\text { * Educación } \\
\text { * Garantías sociales y } \\
\text { código de trabajo } \\
\text { * Justicia } \\
\text { * Cultura, juventud y } \\
\text { deportes } \\
\text { * Mujer y familia } \\
\text { * Ambiente } \\
\text { * Seguridad ciudadana } \\
\text { * Política exterior }\end{array}$ & $\begin{array}{l}\text { * Reflexión nacional } \\
\text { * Oportunidades } \\
\text { creadas en el pasado } \\
\text { * Crisis de los } 80 \mathrm{~s} \\
\text { * Oportunidades } \\
\text { futuras } \\
\text { * Desarrollo social } \\
\text { * Desarrollo } \\
\text { económico } \\
\text { * Desarrollo } \\
\text { ambiental } \\
\text { * Gobernabilidad } \\
\text { * Sostenibilidad } \\
\text { * Papel de la } \\
\text { Asamblea Legislativa }\end{array}$ & $\begin{array}{l}\text { * Trabajo de los } \\
\text { costarricenses } \\
\text { * Necesidades para } \\
\text { el futuro: educación, } \\
\text { infraestructura, } \\
\text { telecomunicaciones, } \\
\text { reducción de tasas } \\
\text { de interés y de } \\
\text { inflación, reforma } \\
\text { fiscal, acceso al } \\
\text { crédito, reforma } \\
\text { laboral, aprobación } \\
\text { del Tratado de Libre } \\
\text { Comercio con } \\
\text { Estados Unidos. } \\
\text { * Aportes de gobier- } \\
\text { nos anteriores. } \\
\text { * "Triángulo de la } \\
\text { Solidaridad” }\end{array}$ \\
\hline
\end{tabular}

En este último período, los MPs se diversifican no en cuanto a la tópica de este tipo de discurso, que cubre fundamentalmente tres ejes: asuntos políticos, asuntos económicos y asuntos sociales, sino más bien a la perspectiva desde la cual los emisores transmiten su mensaje y esperan que sea recibido por los distintos niveles de receptor: diputados, grupos 
políticos / públicos, ciudadanía en general. Precisamente para imprimir esa perspectiva particular, el emisor empieza en este período a titular los MPs ${ }^{9}$. Otro recurso utilizado es el empleo de expresiones nominales claves ("neutralidad", “oportunidades”, “equidad”, etc.), así como expresiones predicativas de gran fuerza retórica: "Doy cuenta de...” (Arias 90).

\section{Conclusiones}

El mandato constitucional del Artículo 139, inciso 4, no hace ninguna mención a la forma que debe tener el Mensaje, excepto por señalar que debe ser escrito. Por ello a lo largo del siglo XX los MPs, tanto en su tamaño como en su organización, varían notablemente. Solo en términos de extensión, hemos visto que los MPs van desde 810 palabras (Figueres F 74) hasta 43.709 (Trejos 70), el MP más largo del período en estudio. Sin embargo, excepto por algunos MPs atípicos (en particular los más cortos), es posible establecer una estructura formal y una estructura de contenidos o tópica bastante sistemática.

En cuanto a los componentes de la estructura formal, el MP consta de:

1. Título [MENSAJE + emisor + receptor + fecha]

2. Marco:

a) Saludo [Vocativo: Señores Diputados]

b) Cierre [(Vocativo: Señores Diputados $)+$ emisor + lugar + fecha]

3. Discurso [exordio + cuerpo + epílogo]

Con base en los componentes estructurales se periodizó el siglo en estudio en cuatro partes, con el fin de determinar la tópica (temas recurrentes) del MP. La tópica del discurso se desarrolla fundamentalmente en la secuencia principal denominada "cuerpo", el cual se analizó en segmentos y sus subsegmentos (estos, a su vez, se componen de párrafos temáticos, pero la temática específica por párrafo no se incluyó en el análisis). Se estableció una matriz por cada uno de los cuatro períodos, las cuales muestras que la tópica general del MP puede resumirse del siguiente modo:

1. Asuntos Internacionales (Relaciones exteriores)

2. Asuntos Nacionales

a) Asuntos económicos: Hacienda y Comercio (ingresos fiscales, egresos, importaciones, exportaciones, crédito, etc.)

b) Asuntos sociales: Educación, Salud, Trabajo, Justicia, Seguridad, etc.

c) Asuntos políticos: campaña electoral reciente, Elecciones, Oposición, relaciones del Poder Ejecutivo con el Poder Legislativo, etc.

d) Obra Pública / Infraestructura / Inversión

e) Reformas constitucionales

El objetivo fundamental de este primer artículo ha sido dar cuenta de la estructura formal y los contenidos (tópica) de un tipo de discurso político identificado aquí como MP (Mensaje Presidencial), como una primera etapa en la caracterización de este tipo de discurso en varios otros niveles: como siguiente paso se hará su descripción como evento discursivo desde la etnografía de la comunicación. En este marco la forma y el contenido del mensaje constituyen el componente lingüístico que, junto con una serie de elementos contextuales relevantes (participantes, escena, género, etc.), dan cuenta de un determinado tipo de evento discursivo. 


\section{Notas}

1. El dígrafo MP que se ha adoptado en esta investigación para referirse al último mensaje de la administración es puramente ad hoc, por cuanto los cuatro informes anuales reciben la denominación "mensaje". Por otra parte, para efectos de este artículo, resulta innecesario especificarlo aún más, por ejemplo con la etiqueta "MP4", lo cual obviamente deberá hacerse si se llega a trabajar con los cuatro mensajes: MP1, MP2, MP3 y MP4. Lo importante aquí es que el MP es un evento discursivo particular en el conjunto de las comunicaciones políticas, y dentro de ellas las del presidente de la república, y dentro de ellas, los informes a la asamblea de los diputados (ver nota 2).

2. Con este término genérico me refiero tanto al Congreso, antes de 1949, como a la Asamblea Constituyente de 1949 y a la actual Asamblea Legislativa.

3. Libro I, Capítulo III de la Retórica; todas las citas corresponden a la edición de 1953 de Antonio Tovar (ver Bibliografía).

4. Obsérvese que los años que se citan corresponden a las fechas de los MPs del corpus y no a las fechas específicas de cuando sucedieron los cambios. La Asamblea Legislativa como tal entró en funciones el 8 de noviembre de 1949, esto es, al día siguiente de la aprobación de la Constitución Política, el 7 de noviembre, por parte de la Asamblea Nacional Constituyente, que cesa en sus funciones ese mismo día (ver artículo 116-VII de las Disposiciones Transitorias del la Constitución Política de 1949).

5. La misma segmentación del período 1902-2002, esta vez con base en los eventos histórico-políticos, se propone en otro componente de la investigación, correspondiente a la contextualización histórica de los MPs. Esa periodización y su justificación serán incluidas en el artículo correspondiente a la descripción del MP como evento comunicativo desde la etnografía de la comunicación de Hymes (1972).

6. Uno de los graves problemas que presenta la compilación de Meléndez Chaverri (1981-1991) es que en la mayoría de los casos, la segmentación está equivocada, es decir, no corresponde a la edición original del MP.

7. De los oratoris officia descritos por Cicerón, dispositio es una "operación retórica que consiste en la elección y puesta en orden de los argumentos más adecuados para el discurso” (Vilches 2007:222).

8. En una etapa posterior de la investigación se pretende analizar los exordios y epílogos desde el punto de vista retórico.

9. Los cuatro MPs de cada administración de este período están titulados y subtitulados.

\section{Bibliografía}

Arguedas, Cecilia. 2000. "Análisis de un discurso político a propósito del Parlamento Centroamericano”. En: Pochet Coronado, R.M. (comp.), 247-277.

Aristóteles. 1953. Retórica. Edición del texto con aparato crítico, traducción, prólogo y notas de Antonio Tovar. Madrid: Instituto de Estudios Políticos.

Brown, Gillian \& George Yule. 1993. Análisis del Discurso. Madrid: Visor Libros. 
Brown, Penelope \& Stephen C. Levinson. 1987. Politeness. Some universals in language usage. Cambridge: Cambridge University Press.

Fernández, Oscar. 1989. "De una teoría de la conciencia al análisis de la producción discursiva”. En: Fernández, Oscar (comp.), 229-258.

Fernández, Oscar. 1989. Sociología: Teoría y métodos. San José: Educa.

Fonseca, Elizabeth (comp.). 1989. Historia: Teoría y métodos. San José: Educa, 267-303.

Givón, Talmy. 1984. Syntax: A functional.typological introduction. Vol 1. Amsterdam: John Benjamins.

González, Alfonso. 1994. El discurso de la Patria. Estructuras simbólicas del poder. San José: Editorial de la Universidad de Costa Rica.

Halliday, M.A.K. \& Ruqaiya Hasan. 1989. Language, context, and text: aspects of language in a social semiotic perspective. Oxford: Oxford University Press.

Hernández, Gerardo. 2000. "El discurso del Pacto Figueres-Calderón. Un ejercicio de análisis estructural del discurso”. En: Pochet Coronado, R.M. (comp.), 209-246.

Hernández Mata, Francisco José. 1995. “La manipulación textual en el discurso de reapertura de la "Universidad Nacional” por el Dr. Rafael Ángel Calderón Guardia, presidente de la República de Costa Rica, año de 1941”. Káñina. Revista de Artes y Letras de la Universidad de Costa Rica. 19 (2): 15-30.

Hymes, Dell. 1972. "Models of interaction in language and social life". En: Hymes, D. y J. Gumperz (eds.), 35-71.

Hymes, D. and J. Gumperz (eds.).1986. Directions in Sociolinguistics. The ethnography of communication. Oxford/New York: Blackwell.

Jiménez Ardón, Óscar. 1993. Cómo hacer análisis ideológico: propuesta de método para analizar ideológicamente un discurso a partir de los discursos del presidente Lic. Rafael Ángel Calderón Fournier a la Asamblea Legislativa, mayo 1990-1992. San José: Centro de Estudios y Publicaciones ALFORJA.

Meléndez Chaverri, Carlos (comp.). 1981-1991. Mensajes Presidenciales. Tomos III-VIII. Biblioteca de la Academia de Geografía e Historia de Costa Rica. San José: Ed. Texto Ldta. (Tomos I-V); Editorama S.A. (Tomo VI); Imprenta Nacional (Tomos VII-VIII).

Mena, Rosibel y Annette Soto. 1997. Análisis del juego táctico utilizado por José María Figueres Olsen en sus discursos presidenciales de mayo 1994,1995,1996 y 1997. Tesis de licenciatura en Periodismo: Universidad de Costa Rica. 
Monge Alfaro, Carlos. 1974. Historia de Costa Rica. San José: Librería Trejos.

Pendones de Pedro, Covadonga. 1991. Análisis del discurso político en Centroamérica. Tesis de doctorado en Lingüística: Universidad Autónoma de Madrid.

Pochet Coronado, Rosa María (comp.). 2000. Discurso y Análisis Social. San José: Editorial de la Universidad de Costa Rica.

Quesada Camacho, Juan Rafael. 1989. "Historiografía: Elementos para su estudio". En: Fonseca, Elizabeth (comp.), 267-303.

Quesada Pacheco, Jorge Arturo. 1989. “Aportes de la lingüística al estudio del discurso persuasivo". Revista de Filología y Lingüística. 15 (1): 145-147.

1994. "Política y sociolingüística". Revista de Ciencias Jurídicas. 78 (Mayo-Agosto): 85-96.

1997. Los discursos de los políticos de Costa Rica. San José: EUNED.

2001. Estrategias de los políticos para solicitar nuestros votos. Heredia: EUNA.

Rojas, Magda Inés. 1980. El Poder Ejecutivo en Costa Rica. San José: Editorial Juricentro.

Salazar Mora, Orlando y Jorge Mario Salazar Mora. 1991. Los Partidos Políticos en Costa Rica. San José: EUNED.

van Dijk, Teun. 1998. Ideology. A multidisciplinary approach. London: Sage.

1999. “QQué es el análisis del discurso político?”. En: van Dijk, T. e Iván Rodrigo, 9-103.

2001. "Texto y contexto de los debates parlamentarios". Revista Electrónica de Estudios Filológicos. 2: 1-45. En: http://www.um.es/tonosdigital /znum2/estudios/ TAvanDijkTonos2.htm. Consulta: 01/12/2007.

van Dijk, T. e Iván Rodrigo. 1999. Análisis del Discurso Social y Político. Quito: Abya Yala.

Vilches, Fernando et al. 2007. Manual de Retórica Parlamentaria. Madrid: Asamblea de Madrid.

Zamora Ovares, Óscar. 2000. El discurso político como instrumento de dominación: los discursos presidenciales de José María Figueres Olsen de 1995 a 1998. Tesis de licenciatura en Sociología: Universidad de Costa Rica.

Zeledón Torres, Fernando. 1991. La Paz y el Discurso Político Nacional: los casos de los discursos del Dr. Oscar Arias Sánchez y del periódico La Nación 1985-1987. Tesis de maestría en Sociología: Universidad de Costa Rica. 


\section{Anexo 1. Lista de los títulos de los MPs del corpus}

NB: La barra oblicua indica los retornos de cada línea en la portada impresa de cada MP original.

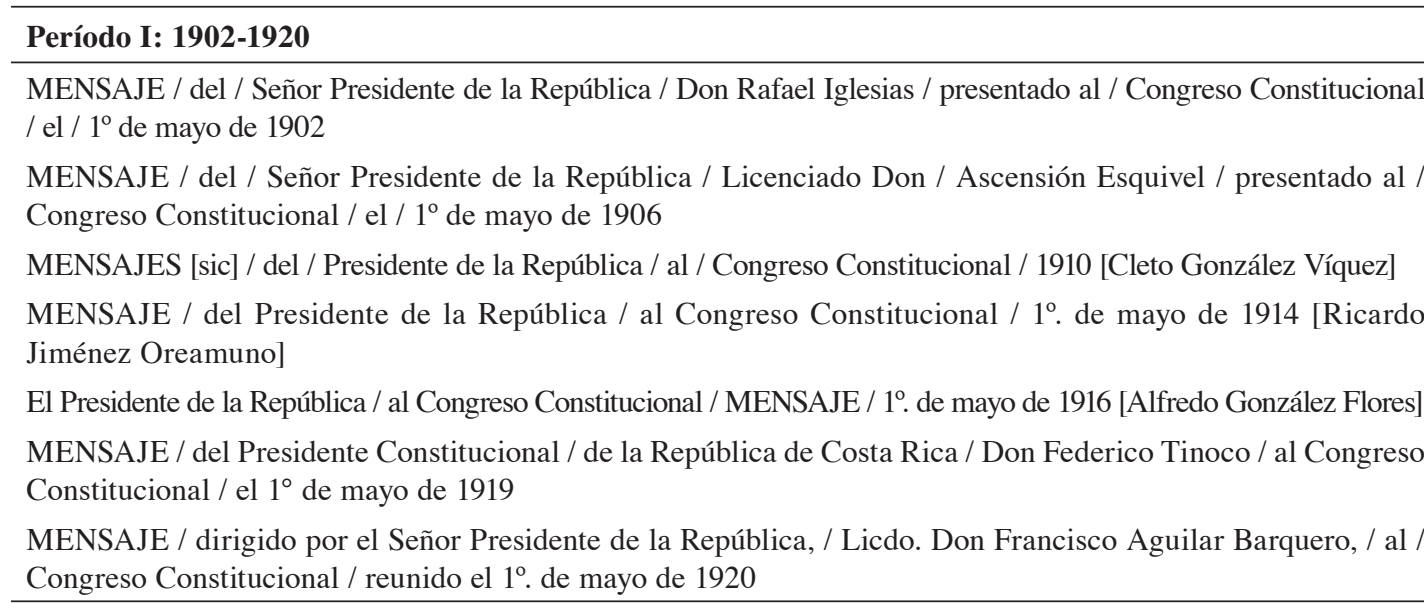

Período II: 1924-1949

MENSAJE / del Presidente de la República / Don Julio Acosta García / presentado al / Congreso Constitucional / el día $1^{\circ}$ de mayo de 1924

MENSAJE / de / Don Ricardo Jiménez / Presidente de la República / al / Congreso Constitucional / 1º de mayo de 1928 MENSAJE / del / Presidente de la República / al / Congreso Constitucional / 1 de mayo de 1932 [Cleto González Víquez]

MENSAJE / de / Don Ricardo Jiménez / al / Congreso Constitucional / 1º de mayo de 1936

MENSAJE / del Licenciado Don León Cortés / al Congreso Constitucional / 1º de mayo de 1940

MENSAJE / del Señor Presidente de la / República, Doctor Don / R. A. Calderón Guardia / presentado al / Congreso Constitucional / el 1 ${ }^{\circ}$. de mayo de 1944

MENSAJE / del Señor Presidente de la / República Licenciado Don / Teodoro Picado / presentado al / Congreso Constitucional / el 1o. de mayo de 1947

MENSAJE Presidencial / presentado a la / Asamblea Nacional Constituyente / de la / Segunda República de Costa Rica / por / Don José Figueres Ferrer / Presidente de la Junta Fundadora de la Segunda República /el 16 de enero de 1949

\section{Período III: 1953-1982}

MENSAJE / del Señor Presidente / Constitucional / de la República Don / Otilio Ulate / presentado a la / Asamblea Legislativa / el 1o. de mayo de 1953

MENSAJE / del Señor Presidente de la República Don José Figueres / 1º de mayo de 1958

MENSAJE / del Señor Presidente de la República / Lic. Don Mario Echandi / presentado a la / Asamblea Legislativa / el $1^{\circ}$. de mayo de 1962

MENSAJE / del Señor Presidente Constitucional de la República / de Costa Rica, Don Francisco J. Orlich / $1^{\circ}$. de mayo de 1966

MENSAJE / del Presidente de la República / de Costa Rica / José Joaquín Trejos Fernández / 1º de mayo de 1970 Discurso / del / Señor José Figueres Ferrer / Presidente de la República de Costa Rica / 1º de mayo de 1974 Ultimo Informe Presidencial / de Mi Administración / Presidente Daniel Oduber Quirós / San José, 1o. de mayo de 1978 / Asamblea Legislativa

Discurso / del Señor Presidente / de la República / Lic. Rodrigo Carazo / a la Asamblea Legislativa / 1o. de mayo 1982 


\section{Período IV: 1986-2002}

MENSAJE Presidencial / Justicia Social con Libertad / Discurso del Presidente de la República / Don Luis Alberto Monge / el $1^{\circ}$ de mayo de 1986

Entrego una Costa Rica Más Grande / MENSAJE del Presidente de la República / Dr. Oscar Arias Sánchez $/ 1^{\circ}$. de mayo de 1990.

MENSAJE del Señor / Presidente de la República / Lic. Rafael Ángel Calderón Fournier / ante la Honorable Asamblea Legislativa / Caminos de Prosperidad / San José, Costa Rica, $1^{\circ}$. de mayo de 1994

Una Sociedad Preparada Para El Futuro / MENSAJE del Señor Presidente de la República / José María Figueres Olsen, / sobre el Estado de la Nación / Asamblea Legislativa / 1º de mayo de 1998

Costa Rica Se Moderniza / MENSAJE a la Asamblea / Legislativa del Presidente / de la República, / Miguel Ángel Rodríguez Echeverría / 1 ${ }^{\circ}$. de mayo de 2002 
